Departamento de Historia

Universidad de Santiago de Chile

Revista de Historia Social

y de las Mentalidades

Volumen 24, $\mathrm{N}^{\circ} 1,2020: 31-84$

Issn On Line: 0719-4749

\title{
MODALIDADES DE LECTURA Y USO DE UN "ARCHIVO DE LA REPRESIÓN” EN EL ÁMBITO CIENTÍFICO-ACADÉMICO*
}

\author{
MODES OF READING AND USE OF AN "ARCHIVE OF REPRESSION" \\ IN THE SCIENTIFIC-ACADEMIC FIELD
}

\author{
DrC. ALEX DARIO COLMAN** \\ Universidad de Buenos Aires \\ Ciudad Autónoma de Buenos Aires, Argentina \\ Email: alexdcolman@gmail.com \\ Id-ORCID: 0000-0002-8241-2177
}

\begin{abstract}
RESUMEN
Este artículo estudia las modalidades de lectura y uso de la documentación obrante en el archivo de la Dirección de Inteligencia de la Policía de la Provincia de Buenos Aires (DIPBA) en el ámbito científico-académico. A partir de un corpus de artículos de investigación científica, investigamos los usos de este archivo a partir del análisis estadístico y reconstruyendo la topografía de relaciones intertextuales entre la documentación y las publicaciones académicas examinadas. En segundo lugar, analizamos los modos de lectura y presentación de la documentación registrados en la discursividad de los artículos, focalizando en los efectos discursivos y enunciativos asociados al uso del archivo. Como aproximación inicial a
\end{abstract}

\begin{abstract}
This article studies the modes of reading and use of the documents of the archive of the Police Intelligence Directorate of the Province of Buenos Aires (DIPBA) in the scientificacademic field. Using a corpus of scientific research articles, we investigate the uses of this archive based on statistical analysis and reconstructing the topography of intertextual relationships between the documentation and the academic papers examined. Secondly, we analyze the modes of reading and presentation of the documentation registered in the discursiveness of the articles, focusing on the discursive and enunciative effects related to the use of the archive. As an initial approach to the
\end{abstract}

* Recibido: 20 de diciembre de 2019. Aprobado: 15 de febrero de 2020.

** Artículo científico. Esta contribución proviene de la investigación doctoral en curso "Las emociones como efectos de sentido. Un estudio del impacto afectivo del archivo de la Dirección de Inteligencia de la Policía de la Provincia de Buenos Aires (DIPBA) en la discursividad de sus investigadores y archivistas", financiada por la Agencia Nacional de Promoción Científica y Tecnológica y desarrollada en el marco del programa de doctorado en Lingüística. Facultad de Filosofía y Letras de la Universidad de Buenos Aires (Argentina). 
las gramáticas de reconocimiento del archivo de la DIPBA, se describen algunos de los efectos producidos en el reconocimiento contemporáneo de su documentación, en el propósito de explorar aristas del trabajo de producción de representaciones sobre la represión y el pasado reciente en Argentina.

Palabras clave: Archivo; DIPBA; modos de lectura; modalidades de uso grammars of recognition of the DIPBA archive, we describe some of the effects produced in the contemporary recognition of its documentation, in order to explore edges of the production of representations about the repression and the recent past in Argentina.

Keywords: Archive; DIPBA; Modes of Reading; Modes of Use

Cómo citar: Colman, Alex Dario. (2020). "Modalidades de lectura y uso de un "archivo de la represión" en el ámbito científico-académico". Revista Historia Social y de las Mentalidades, 24(1), 31-84. DOI: $10.35588 /$ rhsm.v24i1.4287.

\section{INTRODUCCIÓN}

Este artículo explora aspectos del reconocimiento contemporáneo del archivo de la Dirección de Inteligencia de la Policía de la Provincia de Buenos Aires (DIPBA), considerado uno de los archivos de la represión más importantes de Argentina y Latinoamérica. ${ }^{1}$ Se trata de una primera aproximación en torno a los usos de este archivo como fuente documental y objeto de estudio. Particularmente, se observan las modalidades de lectura y uso de su documentación en el ámbito científico-académico, específicamente en los estudios históricos, a partir de una propuesta que integra métodos cuantitativos y cualitativos. La articulación teórico-metodológica se plantea en el marco de una perspectiva multidisciplinaria de carácter cualitativo, que focaliza en la práctica interpretativa del análisis estadístico, el análisis de redes sociales y el análisis del discurso como distintos modos de aproximación a las lecturas y usos de este archivo.

Mediante el relevamiento de un corpus de artículos de investigación científica en los que se aborda, utiliza o menciona el archivo de la DIPBA, examinamos los modos en que ha sido empleada y leída su documentación con el propósito de estudiar aristas del trabajo de producción de representaciones sobre el pasado reciente en el ámbito científico-académico en Argentina.

El análisis se estructura en dos partes. La primera aporta una visión panorámica de los usos del archivo en el ámbito elegido mediante el relevamiento

1 Agradezco a los revisores por las sugerencias críticas que contribuyeron a mejorar sustancialmente el trabajo. 
de las publicaciones académicas y de su análisis estadístico, y una representación topográfica de las relaciones entre la documentación y los artículos, utilizando para esto último herramientas del análisis de redes sociales. La metodología de análisis integra, en primer lugar, la construcción de tablas para la clasificación de los artículos según distintas variables y su vuelco en gráficos estadísticos, y en segundo lugar, la construcción de matrices cuadradas binarias que son utilizadas tanto para la creación de redes sociales mediante el programa Visone 2.17 como para el análisis de correlaciones a partir del programa de análisis estadístico JASP 0.11.1. En la segunda parte, examinamos el dispositivo de enunciación ligado a los estudios de historia reciente, focalizándonos en las modalidades de lectura y presentación de la documentación de la DIPBA registrados en la discursividad de los artículos, y en los efectos discursivos y enunciativos asociados al uso del archivo. En este caso, nuestra metodología agrupa herramientas propias del análisis del discurso como práctica interpretativa (Arnoux), y se centra en el análisis de las modalidades de inscripción y especificación discursiva de las instancias de enunciación de los artículos -la construcción, a partir de marcas propias de la redacción científica, de un enunciador y un enunciatario asociados al género "artículo de investigación científica"-, así como la objetivación discursiva de los documentos del archivo -su constitución como "objeto de estudio" o como "fuente"-, y la puesta en relación entre las instancias de enunciación y la documentación.

A través de esta primera aproximación a los usos y lecturas del archivo de la DIPBA, nuestro objetivo es indagar los modos en que una diversidad de actores, situados en un dominio o ámbito específico -el científico-académico-, participa de distintas formas en el establecimiento de este archivo como lugar de memoria y en su constitución como objeto de estudio científico. La elección del ámbito científico-académico se fundamenta en la influencia que éste ha tenido en la repercusión de las reflexiones sobre el pasado reciente en Argentina. Dicha influencia es materia de interpretaciones diversas. Algunos analistas sostienen que "en la Argentina la memoria ha monopolizado los debates en torno a las representaciones del pasado, evidenciándose un proceso de expulsión de la historia de la memoria, que ha desacreditado la disciplina histórica frente a la memoria viva" (Guglielmucci 128). Desde esta perspectiva, si bien se registra un impulso renovado de la investigación histórica en el ámbito científico-académico, la proliferación de memorias sobre el pasado habría generado una multiplicación de los enunciadores del saber histórico, borrando las diferencias entre la doxa o la opinión y el conocimiento histórico "legítimo, sometido a procedimientos de discusión y verificación entre los especialistas y respaldado por la institución universitaria" (Vezzetti 25). Otros estudiosos han planteado, en cambio, que se 
trataría de "una frontera porosa entre el espacio académico y el de los militantes y gestores de DDHH [Derechos Humanos], donde la desconfianza mutua suele romperse ya sea por vínculos personales, afinidades ideológicas o de trayectoria de vida [...]" (Guglielmucci 129). En todo caso, algunas investigaciones han evidenciado la articulación entre académicos, gestores y activistas de derechos humanos en ámbitos de trabajo comunes y la formulación de inquietudes políticas similares, mostrando que

La divulgación de las investigaciones realizadas, a través de libros, congresos y jornadas abiertas a la sociedad, ha permitido que varios estudiosos sean reconocidos como expertos en dominios que no son los académicos y sean convocados a participar como oradores principales en actividades organizadas por activistas de la memoria, ya sea con la finalidad de enriquecer el intercambio de experiencias o abrir el debate sobre determinados temas relativos a proyectos conmemorativos puntuales. (Guglielmucci 82)

Si bien se trata de un proceso que mantiene coincidencias muy notorias con otros países de la región -específicamente Brasil, Chile y Uruguay- "dado el peso de las experiencias dictatoriales como estructurantes del campo [historiográfico] y sus preocupaciones" (Franco 192), en Argentina en particular la prolificidad de los estudios sobre memorias e historia reciente ${ }^{2}$ ha repercutido en la creación de numerosos emprendimientos académicos, diversas experiencias y procesos de consolidación en los que es posible detectar "una agenda de temas y problemas que se han ido ampliando y complejizando, acompañada de emergencias y de reflexiones sobre los desafíos y los aportes de nuevas fuentes y metodologías que marcan a la tarea de investigación" (Flier y Kahan 154). Esto ha generado

2 Los estudios sobre memorias e historia reciente se reconocen como campos autónomos, sin embargo "sus preocupaciones, temas y metodologías resultan, en muchos casos, convergentes" (Flier y Kahan 152).

3 Aunque faltaría nombrar muchos otros espacios valiosos, destacamos -meramente a título de ejemplo- instituciones y redes como el Núcleo de Estudios sobre Memoria del Instituto de Desarrollo Económico y Social (IDES), el Programa Memoria Colectiva y Represión: Perspectivas Comparativas sobre el Proceso de Democratización en el Cono Sur de América Latina, la Red de Estudios sobre Represión y Violencia Política (RER), la Red Interdisciplinaria de Estudios de Historia Reciente (RIEHR), la Asociación de Historia Oral de la República Argentina (AHORA); emprendimientos universitarios como la Maestría en Historia y Memoria de la Universidad Nacional de La Plata, la Maestría en Historia Social Argentina y Latinoamericana de la Universidad Nacional de Rosario, la Maestría en Derechos Humanos y Ciudadanía proveniente de la asociación entre la UNLP y la Universidad Nacional de San Luis, así como otros espacios 
la producción de agendas de investigación específicas, de carácter generalmente interdisciplinario pero con diferentes pesos disciplinares según los casos.

Por otra parte, aunque la distinción analítica entre historia y memoria es necesaria para discernir "mundos de representaciones y de prácticas relativos a los modos como se operan las relaciones entre el pasado y el presente" (da Silva Catela, "El mundo" 205), con metas diferentes tanto en sentido éticopolítico como cognitivo, se ha registrado una hibridación marcada entre ambas modalidades de representación del pasado en el caso de las producciones académicas inscriptas en el ámbito de estudios de historia reciente. En este contexto, ciertos autores sostienen que la doble inscripción -a la vez política y académica- de las posiciones de enunciación de una determinada generación de investigadores ha jugado un rol clave en la repercusión académica y pública de las reflexiones sobre el pasado reciente (Acha 3).

No obstante la dominancia de determinados anclajes institucionales, el presente trabajo es un estudio de caso que intenta mostrar la complejidad y variabilidad de los usos científico-académicos del archivo de la DIPBA. Su utilización como fuente u objeto de estudio trasciende los marcos institucionales de los estudios sobre memoria e historia reciente, articulándose a una multiplicidad de abordajes. En este contexto, nuestro objetivo es aproximarnos a los modos en que una diversidad de actores inscriptos en el ámbito científicoacadémico participan en la "lugarización" y "objetivación" del archivo de la DIPBA.

\section{LOS ARCHIVOS DE LA REPRESIÓN}

Los archivos de la represión hacen referencia a acervos documentales de las instituciones represivas legales e ilegales cuyos procesos de apertura comparten características en América Latina y otras partes del mundo, habiendo sufrido la destrucción y/o conservación, en diversas medidas, según las políticas adoptadas en los países que fueron atravesados por regímenes represivos (Marengo, "Los mecanismos" 153).

vinculados a la Universidad Nacional de Córdoba, la Universidad Nacional de General Sarmiento, la Universidad Nacional del Litoral, la Universidad Nacional de San Luis, entre otras; la edición de revistas electrónicas como Clepsidra, Aletheia y Revista Contenciosa; y la realización de encuentros nacionales e internacionales como las Jornadas de Trabajo sobre Historia Reciente. Para un abordaje pormenorizado sobre algunos de estos emprendimientos, se puede consultar Flier y Kahan; Franco; Luciani. 
Entre los fondos más importantes que han sido objeto de investigaciones en el ámbito latinoamericano, se encuentran el archivo del Departamento Estadual de Ordem Política e Social (DEOPS), que funcionó en varias regiones de Brasil, los archivos de la Secretaría de Seguridad Pública (DOPS), Servicio Nacional de Informaciones (SIN), Consejo de Seguridad Nacional (CSN), Comisión General de Investigaciones (CGI), División de Inteligencia de Departamento de Policía Federal, de ese mismo país, los documentos secretos de la Policía Política de Stroessner -o Archivos del Terror-, y de la Dirección Nacional de Asuntos Técnicos, ambos de Paraguay, el archivo de la Policía Nacional de Guatemala, diversos acervos documentales y administrativos del gobierno dictatorial de Pinochet, en Chile, los archivos de la Gobernación, en México, y el de la Justicia Militar en Uruguay, entre otros.

En Argentina, se han localizado, desclasificado y/o abierto a la consulta pública diversos fondos documentales pertenecientes a instituciones de carácter represivo, tales como el Departamento de Inteligencia de la Policía de Mendoza (D2), el Departamento de Informaciones Policiales de la Policía de Santiago del Estero, la Dirección de Informaciones de la Policía de la Provincia de Córdoba (D2), el Servicio de Inteligencia del Chubut (SICh) y la Unidad 6 de Rawson, la Policía Provincial de La Rioja, la Dirección General de Informaciones (DGI) de Santa Fe, ${ }^{4}$ la Sección Informaciones de la Prefectura Naval Argentina (SIPNA) para la llamada Zona del Atlántico Norte, y la Dirección de Inteligencia de la Policía de la Provincia de Buenos Aires (DIPBA), entre otros. Asimismo, en el Archivo General del Ejército se ha registrado documentación referente a distintas dependencias del mismo, tales como el II Cuerpo del Ejército de Rosario (Águila et al.). Sin embargo, aún existen dificultades para el acceso e investigación de numerosos acervos disponibles, como el de la Secretaría de Inteligencia del Estado (SIDE), a lo que se suman evidencias de la destrucción o eliminación de otros fondos archivísticos. ${ }^{5}$

Los procesos de apertura de los archivos de la represión han estado atravesados por disputas entre grupos de "emprendedores de memoria", agencias estatales, personal técnico y profesional, políticos y periodistas, dando lugar, por la Policía de Santa Fe. Para más información, consultar Águila, "Policías"; Scocco.

5 Distintos testimonios y pruebas constatan la existencia de procesos de documentación de la detención y el destino de las personas desaparecidas por parte del gobierno dictatorial. En 1983 se sancionó el decreto 2726, que sustrajo los archivos de las instituciones represivas al poder del Estado. Por su parte, el Comando en Jefe del Ejército dispuso, por radiograma del 23 de noviembre de 1983, la destrucción de la documentación vinculada con la "lucha contra la subversión" que se encontraba en poder de las fuerzas militares y las fuerzas de seguridad subordinadas. 
lo general, a la creación de comisiones especializadas encargadas de gestionarlos. Dichas discusiones han focalizado, sobre todo, en los tiempos, modalidades de acceso y naturaleza de la desclasificación, así como en los distintos criterios de ordenamiento y conservación documental (Nazar 150) ${ }^{6}$ y en los "límites" de estos archivos, es decir, sus criterios de inclusión y propiedad, normas de acceso y uso (Jelin, La lucha 181-182). Por otro lado, también se ha disputado el carácter de los procesos de apertura, es decir, a qué imperativos remiten en términos políticos e históricos. La proliferación en el discurso político y académico de estas discusiones y la constitución de organismos especializados en torno al cuidado y gestión de los archivos son expresiones de su relevancia como problema social y político.

\subsection{Archivos de la represión y políticas de memoria}

Un repaso por la literatura especializada en archivos de la represión permite registrar discusiones que giran alrededor de la definición y alcance histórico de la noción, así como de los sentidos y alcances de los procesos de desclasificación y apertura a la consulta pública de estos fondos documentales.

Generalmente, la categoría "archivos de la represión" abarca el conjunto de los acervos producidos con el objetivo de la persecución política y la represión. Una definición más amplia de la noción comprende tanto los archivos de las instituciones represivas como aquellos conformados por organizaciones o personas de la sociedad civil (Karababikián 13). Elizabeth Jelin ha reconstruido los procesos de constitución de diversas modalidades de archivo, identificando por lo menos tres tipos diferentes de acervos archivísticos: los de las instituciones represivas; los documentos acumulados sobre la base de listados y denuncias de casos, en general apoyados en las denuncias recogidas por las organizaciones de derechos humanos; y en tercer lugar, acervos diversos y generalmente dispersos, que reúnen "documentos, restos y rastros del período dictatorial" (Jelin, "Introducción" 7).

La relevancia del estudio de estos fondos documentales se encuentra vinculada al proceso de desmantelamiento de regímenes políticos represivos

En 2003, el Poder Ejecutivo Nacional dispuso la creación, en Argentina, del Archivo Nacional de la Memoria con el objetivo expreso de analizar, clasificar y archivar documentación sobre el quebrantamiento de los derechos humanos por parte del Estado y sobre las respuestas sociales e institucionales a dichas violaciones. Sin embargo, autoridades en la materia han destacado que nuestro país carece de una política nacional de archivos que establezca procedimientos estandarizados respecto a la guarda, protección y conservación del patrimonio documental (Lanteri y Nazar 1), y se han interrogado acerca de los distintos criterios de accesibilidad a la documentación (Lorenz 3). 
en todo el mundo que se desarrolla entre la "Revolución de los Claveles" en Portugal, en 1974, y el fin del Régimen del Apartheid en Sudáfrica. Dicho proceso abarca la terminación de las dictaduras militares en América del Sur, la debacle de la Unión Soviética, la desaparición de las dictaduras conservadoras en España, Grecia y Portugal, y de una serie de regímenes represivos en el continente africano (González Quintana, "Archivos" 376). En este sentido, la noción de archivos de la represión adquiere importancia internacional en 1993, con la decisión del Consejo Internacional de Archivos de crear un Grupo de Expertos en Archivos de la Represión, en el marco de su mesa Redonda en México. Efectivamente, en 1995 el Consejo Internacional de Archivos crea una Comisión de Expertos en colaboración con la UNESCO, presidida entonces por el archivero Antonio González Quintana. Dicha comisión ha recomendado la conservación y protección de los archivos producidos por regímenes represivos, considerándolos "Patrimonio de la Humanidad".

No obstante, algunos autores han propuesto la categoría más amplia "archivos de control social" para problematizar la magnitud y complejidad de las actividades de vigilancia político-ideológica a lo largo de todo el siglo XX, irreductible por lo tanto a los regímenes dictatoriales (Marengo, Lo aparente 28). Esto permite visualizar el carácter político que adquiere dicha elección conceptual, dado que lo que aquí pasa a ser enfocado es el vínculo general entre archivos y control social en los regímenes políticos tanto dictatoriales como democráticos. El asunto de las lecturas y usos sociales y políticos de los archivos de la represión se inserta por tanto en una problemática más general, vinculada al carácter disputado de toda reconstrucción social del pasado y su relevancia política para pensar y actuar en el presente.

La naturaleza de los procesos de desclasificación y apertura de estos acervos también ha sido materia de debates. En general, se ha hablado de "patrimonialización" (Villalta Luna 11), "transferencia", "legado" o "donación" (da Silva Catela, "El mundo" 207), "democratización" (Karababikián 5; Aguirre y Villa-Flores 14), "conquista" (da Silva Catela, "Territorios" 22; Flier 86), "recuperación" (González Quintana, "Políticas" 18) y "rendición de cuentas" (accountability) (Caswell 27; Jimerson 28) para referirse a los procesos en los que se ha logrado la cesión legal, parcial o total, de estos acervos a organismos públicos autónomos y/o comisiones autárquicas. Implícitas en el uso de algunas de estas categorías, pueden registrarse preocupaciones en torno a la democratización y transparencia institucionales, donde el carácter secreto o público y el acceso a los archivos estatales juegan un rol prominente. En otros casos, el énfasis está puesto, más bien, en la eficacia de la presión social ejercida por grupos y organizaciones 
de derechos humanos, la cual ha servido para "recuperar" estos acervos y ampararlos de su posible destrucción.

También se registran discusiones en torno a los sentidos y efectos de la apertura de los archivos para el gobierno y la construcción de hegemonía estatal. Así, se ha planteado que los lugares de memoria, en particular los archivos, pueden ser considerados como artefactos, concretos y simbólicos, utilizados por el Estado para afianzar su posición hegemónica. Algunos autores sostienen que si bien el conocimiento, la preservación y la accesibilidad al patrimonio archivístico debería ser considerado como un índice de la democratización efectiva de la sociedad, el control de la información y de su acceso continúa formando parte de la construcción hegemónica del Estado en función del gobierno y el mantenimiento del orden social (Karababikián 5), y se ha planteado que, tanto el secreto que la misma desclasificación recoge, como la nueva condición de circulación y acceso a los documentos, se han constituido en una "prueba de blancura de los gobiernos post-dictatoriales" (Tello 147).

El relevo de estas discusiones nos advierte sobre el carácter problemático inherente a los modos contemporáneos de reconocimiento y uso de estos acervos, así como a sus procesos de desclasificación y apertura. Muestran cómo los usos y sentidos construidos en torno a los archivos se inscriben en políticas de memoria, noción que alude a las distintas formas de gestionar y lidiar con el pasado pero también a las "grandes ofertas de sentido temporal", a las narrativas generales que plantean marcos institucionales, construyen temporalidades diversas y contribuyen a marcar continuidades y rupturas (Rabotnikof 260-261). Dicha inscripción se expresa en que muchos de estos fondos hayan sido utilizados como registros probatorios en causas judiciales contra quienes cometieran delitos de lesa humanidad, y como fuente y corpus para diversos trabajos, investigaciones y políticas de compensación a víctimas de la represión estatal (Vitale y Minardi 84 ), pero se revela sobre todo en la conexión de los procesos de desclasificación y apertura de los archivos con determinadas políticas estatales. Particularmente, se ha planteado que desde comienzos de siglo, el Estado argentino

consolidó un rol como promotor de una política pública que modificó la espacialidad de la memoria, dando lugar a un proceso de creación de nuevas 'instituciones': archivos, centros culturales y museos de sitio. Se pasó así de un problema social al establecimiento de una política de Estado. Esta consagración de la memoria, hubiera sido imposible sin la creación de estos lugares, como resultado de años de disputa y conflictos. (Da Silva Catela, "Prólogo" 10) 


\subsection{Consideraciones sobre el archivo como lugar y territorio}

Desde la perspectiva de los estudios sobre memorias sociales, los archivos de la represión son generalmente conceptuados como lugares de memoria e historia. La noción de lugar de memoria, acuñada por Pierre Nora, remite a aquellos restos o "espacios en los que la memoria cristaliza lo que ha ocurrido en un momento histórico concreto, y esta recuperación del pasado permite la sensación de una continuidad histórica" (Martínez 16). Los lugares de memoria se dan simultáneamente en sentido material, simbólico y funcional, y lo que los constituye "es un juego de la memoria y de la historia, una interacción de dos factores que desemboca en una sobredeterminación recíproca" (Nora 33). En este marco, los archivos "cristalizan de forma reveladora la doble pertenencia a la memoria y a la historia" (da Silva Catela, "El mundo" 205), expresando su doble carácter monumental y documental (Pomian 4004). Si el primero remite al impacto que produce en su espectador o usuario al orientar su imaginación y su pensamiento hacia lo invisible y el pasado, el carácter "documental" del archivo reenvía a un uso específico que, cuando ya no existe, lo constituye como objeto de estudio. De esta forma,

Un archivo puede ser considerado lugar de historia cuando comporta una referencia explícita a los hechos que permiten el trabajo del historiador. Aquí los soportes documentales son instrumentos de conocimiento, enseñan. Como monumentos son lugares de memoria, cuando comportan una referencia explícita que evoca directamente el pasado. El monumento, más que enseñar, hace recordar. (Da Silva Catela, "El mundo" 206)

Considerado como lugar de memoria e historia, la caracterización de un archivo de la represión remite a la triple relación acervo-espacio físico-agentes, cuya configuración define los efectos de sentido que posibilita como artefacto simbólico. Dicha relación puede ser operativizada y dinamizada considerando al archivo como "territorio de memoria", noción que refiere

al proceso de articulación entre los diversos espacios marcados y las prácticas de todos aquellos que se involucran en el trabajo de producción de memorias sobre la represión; resalta los vínculos, la jerarquía y la reproducción de un tejido de espacios que potencialmente puede ser representado por un mapa, donde situamos al territorio. (Da Silva Catela, "Territorios" 22) 
Como afirma Luciana Messina, el concepto de territorio permite pensar, en términos relacionales, "no sólo las marcas de memoria entre sí sino también las prácticas sociales que las producen y reproducen" (Messina 22). La consideración territorial del archivo permite así especificar su participación en los procesos de producción de representaciones sobre el pasado reciente y de afirmación de identidades sociales (da Silva Catela, "El mundo" 215). Por otro lado, la noción de territorio abre otra dimensión, que "trae la carga simbólica del límite impuesto y establecido por la política" (Besse 6) y alude por lo tanto al campo semántico de la marcación territorial, permitiendo asociar conceptos como "conquista, litigio, desplazamiento a lo largo del tiempo, variedad de criterios de demarcación, de disputas, de legitimidades, derechos, «soberanías»" (da Silva Catela, "Territorios" 22). Esta aproximación implica una visión de las políticas de memoria como prácticas de marcación territorial (Fabri 99), donde las marcas e inscripciones que los sujetos producen sobre los espacios permiten la constitución de los lugares de memoria a partir de modalidades de apropiación que involucran alguna forma de construcción de sentido (Messina 12).

Considerando que los archivos de la represión "han ayudado a construir y, en muchos casos, han dado identidad a una estructura estatal" (Vitale y Minardi 73), el análisis de sus usos y apropiaciones se revela, en primer lugar, como un estudio de los "efectos de Estado" que producen. Como realidad fenoménica, el Estado es producido en discursos y prácticas del poder político, pero también en los encuentros cotidianos de las personas con burocracias y agencias estatales, monumentos, rutinas, rituales y discursos de la esfera pública, en los que el Estado es pensado y, sobre todo, vivido como realidad afectiva (Aretxaga 398). En el caso de los archivos de la represión, esta dimensión afectiva de su impacto remite a su carácter de símbolos y "depósitos" de información y "verdad" sobre el terrorismo de Estado, pero también sobre la continuación de la vigilancia político-ideológica en democracia (Funes, "Los libros" 137) y la naturaleza y carácter del Estado contemporáneo.

Desde este punto de vista, los archivos no sólo intervienen en los procesos de clasificación de lo público y lo privado, la historia y la memoria (da Silva Catela, "Territorios" 17), sino que su "lugarización" amerita ser pensada en el marco de políticas que incluyen proyectos, estrategias y producción de efectos y afectos de Estado. Sin embargo, en su constitución como lugares de memoria e de organización espacial, acomodo temporal, especificación funcional, supervisión, vigilancia y representación que crean la apariencia de un mundo fundamentalmente dividido en estado y sociedad o en estado y economía" (Mitchell 183). 
historia también intervienen prácticas de otros actores sociales y políticos. Como señalamos antes, los archivos de la represión han sido considerados como tipos de artefactos que el Estado utiliza para afianzar su posición hegemónica; empero, dada su naturaleza social y políticamente disputada, es posible interrogarse sobre la variabilidad de efectos de sentido producidos en las distintas esferas en las que han tenido impacto directo, particularmente en los ámbitos judicial, periodístico, académico y político, incluyendo el campo de acción de las organizaciones de derechos humanos y el de los archivos como lugares de trabajo. Situados en estas esferas, distintos actores despliegan y articulan prácticas de apropiación y uso de los archivos con funciones y efectos diversos.

\section{EL ARCHIVO DE LA DIPBA}

La DIPBA fue un servicio de inteligencia dependiente de la Policía Bonaerense que existió entre 1956 y 1998. Aunque fue creada en el contexto de la autodenominada "Revolución Libertadora", su archivo guarda documentación que se remonta a 1932, proveniente del fondo documental producido por las anteriores Secciones de Orden Público y Social (Kahan, "Qué represión" 5). Con el cierre de la DIPBA en 1998, su archivo fue cedido a la Comisión Provincial por la Memoria en el año 2000, y abierto a la consulta pública en 2003.

Desde 1956 hasta 1998, la DIPBA sufrió diversas transformaciones, cambios de rango y denominación acordes a los proyectos políticos de cada gobierno, hasta alcanzar la jerarquía de Dirección General de Inteligencia (Marengo, "Los mecanismos" 155). Sus representaciones y modos de clasificación de las tareas y objetos de vigilancia también sufrieron sendas transformaciones (Funes, "Los libros"; Vitale y Bettendorff). Según las distintas coyunturas históricas y los regímenes políticos, la DIPBA informaba a la comunidad política o a la cúpula militar sobre acontecimientos, acciones, modos de organización y producción de los grupos vigilados, evidenciándose un alto grado de penetración en la vida social e íntima de los sujetos por parte de este servicio de inteligencia. Sin embargo, se han registrado discusiones en la literatura académica que relativizan el alcance, amplitud y profundidad de la infiltración y el espionaje político realizado por la DIPBA (Ghigliani 7), aunque también se ha señalado la existencia de sistemas de codificación que jerarquizaban "el grado de veracidad y de confiabilidad de los datos producidos por los distintos aparatos de inteligencia" (D'Antonio, "Vigilancia" 188).

A nivel geográfico, la DIPBA contaba con una sede central en la ciudad de La Plata, donde funcionaba su archivo, dieciséis delegaciones regionales 
distribuidas en el territorio de la Provincia de Buenos Aires, ${ }^{8}$ y una sede -"División Enlace"- que funcionaba como conexión con la comunidad de inteligencia nacional, donde trabajaban los agentes que colaboraban con la SIDE y el Batallón de Inteligencia 601 durante la última dictadura. Algunas de estas delegaciones funcionaban en las instalaciones de otros organismos de las Fuerzas Armadas y organismos de seguridad. Cada delegación tenía vinculaciones con las unidades regionales de la policía y con las comisarías locales, las cuales enviaban documentación sobre diversos asuntos: creación de partidos políticos, aperturas de locales, pedidos de autorización para actos y movilizaciones, entre otras cuestiones. ${ }^{9}$

En cuanto a la organización de las tareas de inteligencia, la DIPBA se encontraba dividida en una serie de secciones o departamentos que fueron cambiando de nombre y rango a lo largo de la existencia del organismo. A la cabeza se hallaba la Dirección General de Inteligencia, bajo cuya dependencia y en carácter de distribuidor funcionaba el Departamento Central de Inteligencia (DCI), que utilizaba la información producida por las delegaciones o el personal de la sede central. En dicha sede también funcionaba la División Central "Archivo y Fichero", encargada de la organización del archivo. Los agentes de campo de la DIPBA parecen haber dependido de la División "Búsqueda" o Departamento Reunión de Información. La coordinación con otros organismos de inteligencia se encontraba a cargo del Departamento de Coordinación y Enlace. La División Contrainteligencia elaboraba las producciones de la Mesa CICIA ("Contrainteligencia"), que reunía información utilizada para fortalecer la seguridad de los organismos represivos. Además, como las producciones textuales organizadas en legajos se estructuraban según mesas y factores, había departamentos abocados a cada mesa de trabajo.

Según un documento organizativo fechado en $1992,{ }^{10}$ la inteligencia era concebida como un ciclo estructurado en cuatro etapas. En la primera-"Dirección de Esfuerzo de Obtención de Información"-, la Dirección de Inteligencia formulaba un "requerimiento" o "plan de obtención de información", momento centralizado de la producción textual, que era distribuido a las delegaciones correspondientes. Difundidos a los agentes de reunión de información, estos

8 Las delegaciones regionales funcionaban en Azul, Bahía Blanca, Capital Federal, Chascomús, Junín, La Matanza, Lanús, Mar del Plata, Mercedes, Morón, Pehuajó, Quilmes, San Martín, San Nicolás, Tigre y Vicente López.

9 Como ejemplo de estas producciones, véase: Archivo DIPBA, Mesa "A”, Factor Político, Serie Registro y actualización de entidades políticas, Subserie Partidos Políticos por localidad.

10 Archivo DIPBA, Mesa Doctrina, "Manual de Inteligencia y Contrainteligencia". 
realizaban la segunda etapa, que podía incluir "trabajo de campo" e infiltración. Una vez reunido el material, se producía la información de inteligencia a partir de su evaluación, clasificación e interpretación, tarea que estaba a cargo de personal especializado e incluía diversos pasos: el registro de la información mediante un "diario de informaciones", la evaluación de la información a partir de códigos que clasificaban las fuentes y el valor y grado de exactitud de la información aportada, y finalmente la interpretación, consistente en la extracción de conclusiones y apreciaciones (Vitale 32-34). La última etapa consistía en la preparación y difusión del producto de inteligencia a la dirección que había realizado el pedido, difusión de la que formaban parte los informes junto con sus adelantos -faxes y comunicaciones telefónicas-, sus ampliaciones y material adjunto -fotos, recortes de prensa y documentos secuestrados-.

No obstante, la producción de informes de inteligencia podía deberse a diferentes razones y circunstancias, incidiendo en la estructura total del ciclo. Según la información del cuadro clasificatorio de la Comisión Provincial por la Memoria, en algunos factores y series predominan las solicitudes de distintos organismos y autoridades, por ejemplo pedidos de antecedentes de trabajadores por parte de las patronales de ciertas empresas.

Fuera cual fuera el camino concreto de producción de inteligencia, finalmente los productos eran centralizados en la División Central "Archivo y Fichero". Según el documento "División Central documentación-registro y archivo", de 1983, la confección de los legajos y la estructuración del archivo en mesas era realizado por la División Central "Archivo y Fichero", definida como "el receptáculo de toda la información explotada o no por el Departamento Central de Inteligencia (DCI) [...] Está compuesta por distintas mesas de trabajo con las mismas denominaciones que poseen los factores que integran el organismo". ${ }^{11}$ El Archivo se encontraba organizado en torno a un gran fichero, cuyas fichas remitían a los legajos. El personal de inteligencia de la antedicha sección consignaba la información obtenida y la ingresaba en legajos clasificados según un determinado criterio. La clasificación suponía, en primer lugar, la determinación de un factor -el criterio clasificatorio más amplio-, indicado por las delegaciones que remitían la información; luego, su distribución en mesas -divisiones de carácter temático que incluían, por lo general, varios factores-, con denominaciones alfabéticas, subdivididas a su vez en carpetas donde se ubicaban los legajos. De esta manera, el legajo o expediente -unidad documental archivo". 
del archivo-agrupa una serie de documentos de diversos géneros y procedencias en torno a un mismo asunto. Como señala Emmanuel Kahan,

La tarea cotidiana -el "trabajo de campo"-, realizada por agentes policiales, de búsqueda y producción de información, se complementó con la labor burocrático-administrativa de elaboración de informes, fichaje y anexión del material relevante de las organizaciones observadas. (Kahan, "Qué represión" 9)

En 1998, en el marco de un proceso de cuestionamiento social y político a la policía bonaerense que derivó en la reforma policial y en la disolución y replanteo del área de inteligencia de la Policía de la Provincia de Buenos Aires (Estévez 71), la DIPBA fue cerrada por Resolución no. 9 del Ministerio de Seguridad y Justicia de dicha provincia. En un contexto político signado por la emergencia de los "Juicios por la Verdad", la documentación del archivo fue secuestrada por la Cámara de Apelaciones de La Plata.

En el año 2000, el edificio que funcionaba como sede central de la DIPBA y su archivo fueron cedidos a la Comisión Provincial por la Memoria, organismo autárquico creado en el marco de un acuerdo interbloques de la legislatura provincial. ${ }^{12}$ Los integrantes de la comisión ingresaron al edificio en el año 2001. Se realizaron muestras de la documentación y peritajes orientados a su uso como material probatorio en causas judiciales. Posteriormente, se establecieron herramientas archivísticas (inventarios y cuadros clasificatorios) y se implementaron diversas estrategias de difusión. ${ }^{13}$ El peritaje realizado por la comisión divide el archivo en mesas, factores, series y subseries. Estas últimas responden a los distintos procedimientos administrativos utilizados por cada mesa para la organización de las informaciones.

A partir del año 2003, el archivo fue abierto a la consulta pública. En los primeros años, las entregas de documentación al público se orientaron a personas e instituciones afectadas en la última dictadura militar. Con el paso del tiempo se ampliaron los colectivos y la provisión de documentación vinculada

12 Según señalan algunos autores, el interés de esta comisión por entablar diálogos con intelectuales "se convirtió en el puente de encuentro con el campo académico, nacional e internacional" (Flier y Kahan 161-162), lo que se vio reflejado en la organización de encuentros internacionales con expertos invitados del ámbito académico latinoamericano, norteamericano y europeo.

13 Esta información fue recogida de la exposición de Magdalena Lanteri en la Mesa Redonda "En torno al archivo DIPBA. Reflexiones sobre la imagen, el discurso y la memoria", realizada el 15 de noviembre de 2018 en el Centro Cultural de la Memoria Haroldo Conti. 
a otros períodos históricos. La comisión ha elaborado selecciones documentales ("colecciones") que han sido utilizadas por diversos estudiosos, y ha atendido numerosos repertorios de investigación.

Las consultas temáticas para la investigación histórica, periodística o comunitaria se realizan mediante dos formas predeterminadas de acceso, preservando en ambos casos el derecho a la intimidad. ${ }^{14}$ La primera es a través de referencistas de la comisión. En este caso, se debe completar un formulario de solicitud señalando el tema de investigación con una serie de palabras clave y estableciendo criterios de recorte espaciales y temporales. Las entregas de documentación se realizan en formato impreso o digital. La segunda forma de consulta es la realizada in situ, por vía individual mediante la firma de un compromiso de confidencialidad o para investigadores comprendidos en los convenios entre la comisión y diversas instituciones, organismos de derechos humanos, universidades, organizaciones políticas, sociales o gremiales. En este caso, se permite a los investigadores el acceso y búsqueda en las bases de datos del archivo, aunque algunas de las mesas sólo pueden ser consultadas a través de referencistas por su carácter extremadamente sensible.

\section{USOS DEL ARCHIVO DE LA DIPBA EN EL ÁMBITO CIENTÍFICO-ACADÉMICO}

Desde el año 2003, el archivo de la DIPBA ha sido utilizado asiduamente por investigadores inscriptos en una multiplicidad de disciplinas. Esto se ha reflejado en la producción de numerosas publicaciones, lo que ha constituido a este "archivo de la represión" como uno de los más investigados y utilizados en el ámbito científico-académico en América Latina.

En este apartado nuestro objetivo es aportar una visión panorámica de los usos académicos de este acervo, mediante el relevamiento, clasificación y análisis estadístico de las publicaciones a las que ha dado a lugar. Asimismo, utilizamos herramientas del análisis de redes sociales con la intención de indagar acerca de la agenda temática de un conjunto de estas investigaciones y su relación con la proveniencia de la documentación del archivo que utilizan. Para esto, hemos clasificado dichas publicaciones según distintas variables cuyos resultados hemos volcado en la construcción de gráficos estadísticos, y por otro lado, hemos elaborado matrices cuadradas binarias utilizadas tanto para la creación

14 Véase: "Protocolo para la consulta y el acceso" en http://www.comisionporlamemoria.org/ archivo/consultas/. 
de redes sociales mediante el programa Visone 2.17 como para el análisis de correlaciones a partir del programa de análisis estadístico JASP 0.11.1.

A partir del relevamiento de las publicaciones que mencionan el archivo de la DIPBA, hemos reunido un corpus de 614 producciones que hemos clasificado según los siguientes ejes: año de publicación, género discursivo, contexto impreso o digital de aparición, disciplina, tipo de uso del archivo, objeto de estudio de la publicación, período temporal analizado y documentación del archivo citada. De este archivo general -que incluye artículos científicos, artículos de difusión, libros, capítulos, ponencias, conferencias, tesis, tesinas, reseñas, programas, proyectos, planes de trabajo, entrevistas e informes- hemos elegido examinar las producciones pertenecientes al género "artículo de investigación científica", que representan aproximadamente un $48 \%$ del total del corpus.

Gráfico 1: Porcentaje de publicaciones por género discursivo.

\begin{tabular}{|c|c|c|}
\hline \multicolumn{3}{|c|}{ 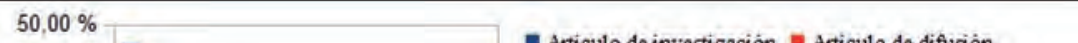 } \\
\hline $45,00 \%$ & Capitulo de libro & - Conferencia \\
\hline $40,00 \%$ & Dossier & Entrevista \\
\hline $35,00 \%$ & - Honors Project & Informe \\
\hline $30,00 \%$ & Libro & = Plan de Tesis de Doctorado \\
\hline & Ponencia & E Programa \\
\hline $25,00 \%$ & Proyecto & Relatoria \\
\hline $20,00 \%$ & Reseña & Seminario \\
\hline $15,00 \%$ & Tesis de Doctorado & = Tesis de Grado / Licenciatura \\
\hline $10,00 \%$ & & \\
\hline $5,00 \%$ & & \\
\hline $0,00 \%$ & & \\
\hline
\end{tabular}

Fuente: Elaboración propia.

El relevamiento fue realizado a partir de búsquedas de producciones del período 2004-2018 dentro de la base de datos de Google Académico, considerada por ciertos analistas como una de las bases más útiles para medir el impacto de las publicaciones científicas (Dávalos-Sotelo 8). La clasificación fue realizada mediante la construcción de una tabla de datos que inventaría las publicaciones según los ejes seleccionados. Para la presentación de los resultados de la clasificación, se ha escogido construir categorías inclusivas para el eje "objeto de estudio de la publicación". Respecto del eje "período temporal analizado", se han tomado en consideración los cortes cronológicos aportados por una perito del archivo DIPBA (Jaschek 5) con el objeto de reconstruir y caracterizar las 
cualidades de la persecución política en relación con la posición de la DIPBA en el organigrama de la policía, la relación con las Fuerzas Armadas, y los destinatarios de la vigilancia político-ideológica (Kahan, "Qué represión" 7). Dichos cortes dividen la documentación en los siguientes períodos: 1930-1955 (antecedentes de la DIPBA), 1956-1960 (orígenes y creación del archivo), 1960-1970 (década del sesenta), 1970-1975 (fin de la denominada "Revolución Argentina" y gobierno peronista), 1976-1983 (intervención durante la dictadura militar) y 1984-1998 (transición y período democrático hasta el cierre de la DIPBA). La elección de dicho criterio se desprende de la necesidad de homogeneizar las condiciones de reconocimiento y lectura de la documentación del archivo. A esto sumamos un último corte, representado por el período 1998-actualidad. Por último, en el eje "documentación del archivo citada" se ha seleccionado, para los fines de esta publicación, solamente la información referida a las mesas y factores que organizan el archivo.

Los resultados del análisis estadístico muestran, en primer lugar, una tendencia al aumento exponencial, a lo largo de los años, de los artículos que mencionan o utilizan de alguna manera el archivo de la DIPBA (Gráfico 2), y en particular, de los que usan el archivo como fuente u objeto de estudio (Gráfico 3), desde el momento de su apertura a la consulta pública.

Gráfico 2: Cantidad de artículos por año.

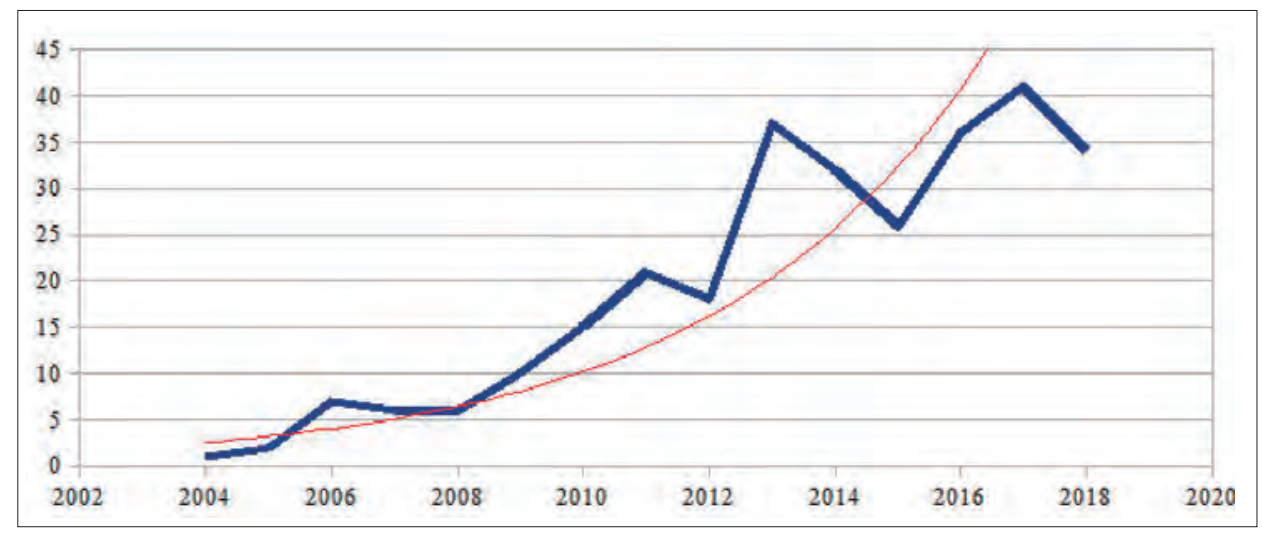

Fuente: Elaboración propia. 
Gráfico 3: Cantidad de artículos por año que usan el archivo de la DIPBA como fuente u objeto de estudio.

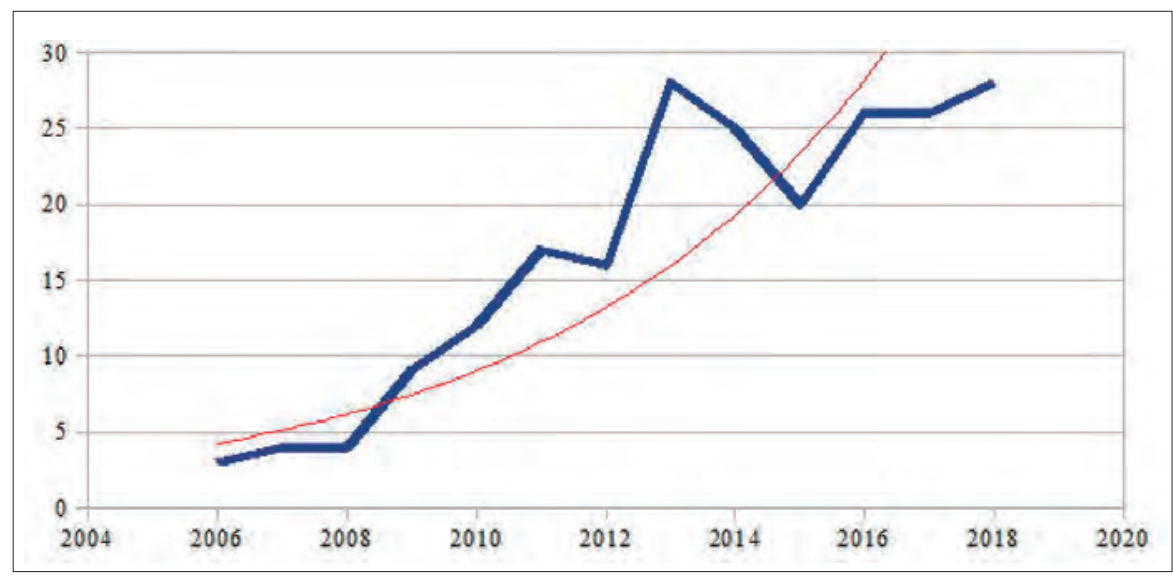

Fuente: Elaboración propia.

Sobre los usos del archivo, encontramos que su aprovechamiento como fuente documental abarca un $60 \%$ del total (Gráfico 4), lo que se corresponde con la inscripción mayoritaria de los artículos del corpus en las disciplinas históricas (Gráfico 5). Por su parte, los artículos que sólo mencionan el archivo de la DIPBA representan un 25\% del corpus, mientras que los abordajes de la DIPBA y su archivo como objetos de estudio representan un $15 \%$.

Gráfico 4: Porcentaje de artículos por tipo de uso del archivo.

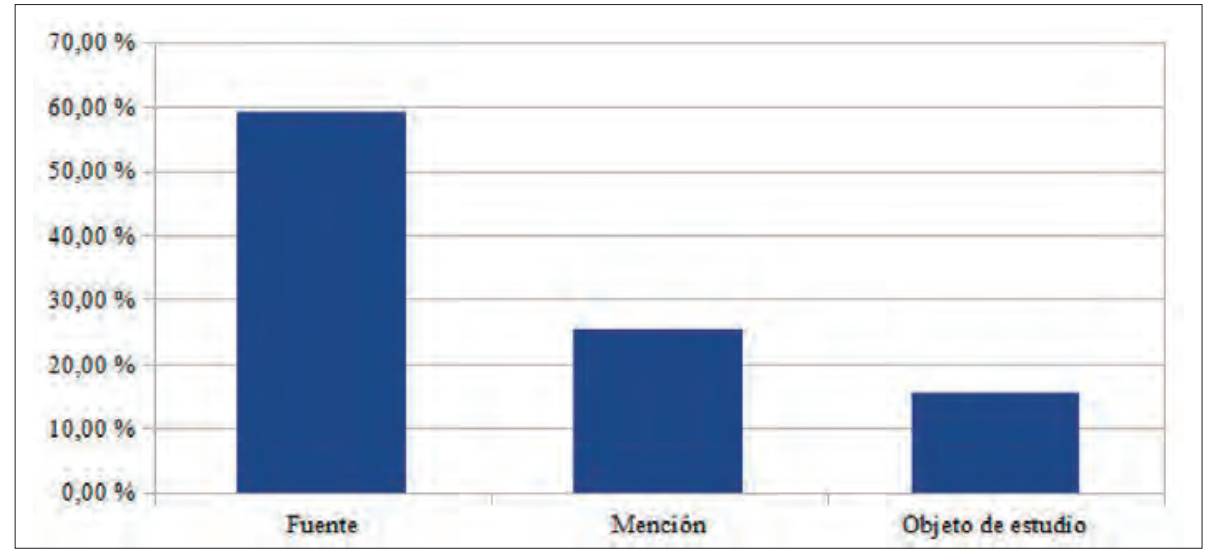

Fuente: Elaboración propia. 
En cuanto a la inscripción disciplinaria de los artículos científicos, casi un $64 \%$ se encuentran comprendidos en los estudios históricos e historiográficos, el $20 \%$ se inscribe en investigaciones sociológicas y antropológicas, el $5 \%$ en análisis del discurso y el 4\% en archivística y bibliotecología. El 7\% restante se reparte entre los estudios visuales, las ciencias de la comunicación, las ciencias políticas, las ciencias jurídicas, la criminología y los estudios artísticos y literarios. Se debe tener en cuenta que existen hibridaciones disciplinares importantes, dado que gran parte de las investigaciones pueden ser consideradas de carácter interdisciplinario.

Gráfico 5: Porcentaje de artículos por disciplina.

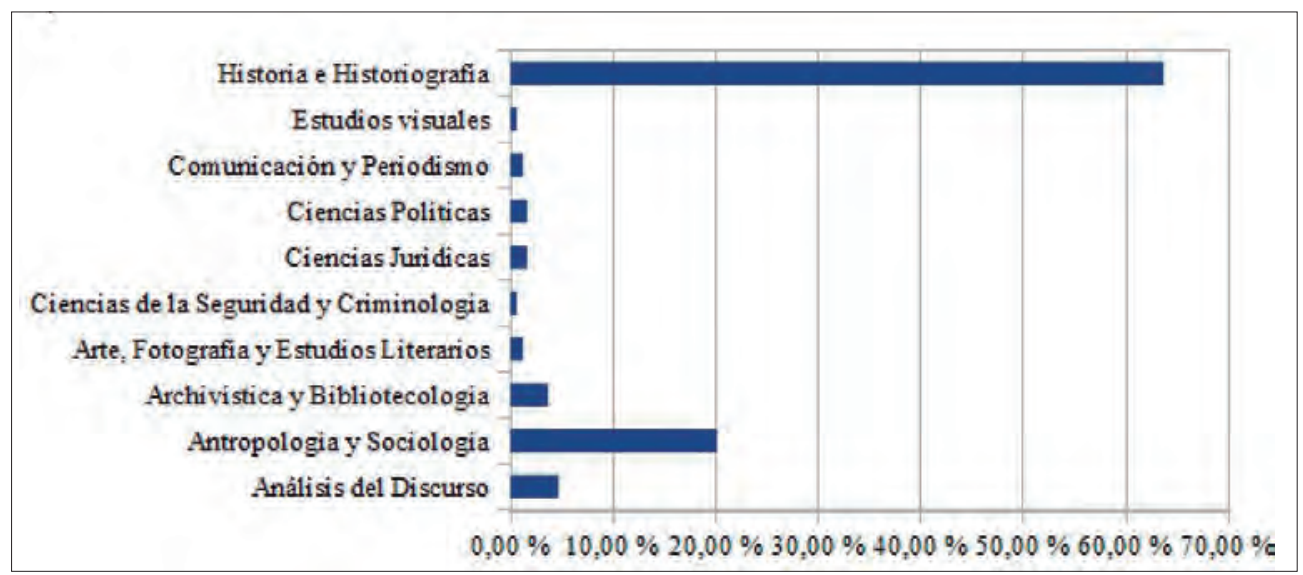

Fuente: Elaboración propia.

En relación a los cortes históricos abordados en los artículos, registramos que los períodos más investigados son, en primer lugar, 1970-1975 y 1976-1983, seguidos por la década de los sesenta y el corte 1998-Actualidad (Gráfico 6). El corte menos estudiado es el que corresponde a la posdictadura, con sólo un 14\% de los artículos que lo abordan. 
Gráfico 6: Porcentaje de artículos por periodo histórico abordado.

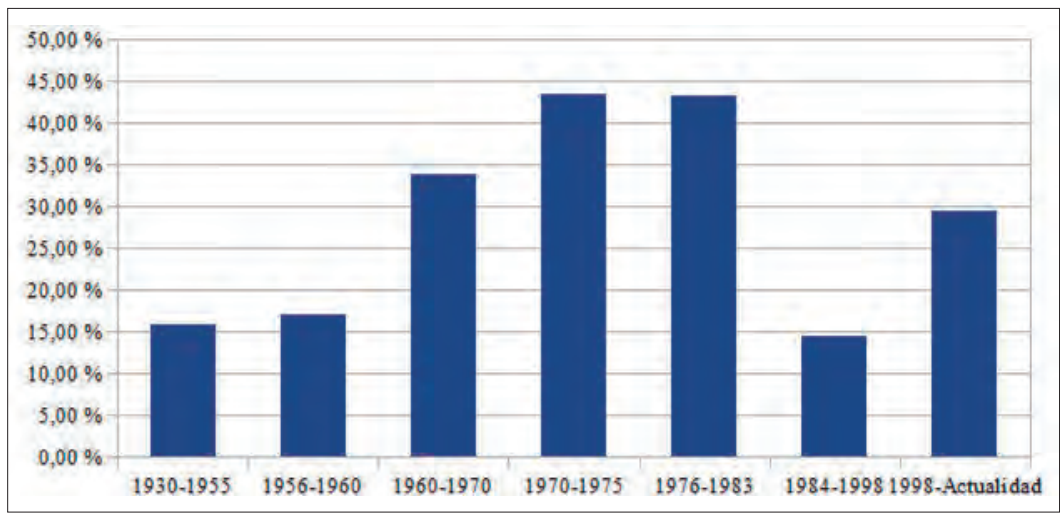

Fuente: Elaboración propia.

Respecto de los materiales del archivo referenciados en los artículos del corpus, registramos que las mesas más consultadas son, en primer lugar, la Mesa "Ds" (Delincuente subversivo, Factor Policial y Operacional, Carpetas Daños y Material Bélico), seguida por la Mesa "A" (Factor Estudiantil y Político), la Mesa "B" (Factor Económico, Gremial y Laboral) y la Mesa "Referencia" (trabajada indistintamente por el personal de las otras mesas, y que contiene información que no podía ser clasificada dentro de los demás factores).

Gráfico 7: Documentación del archivo citada en los artículos.

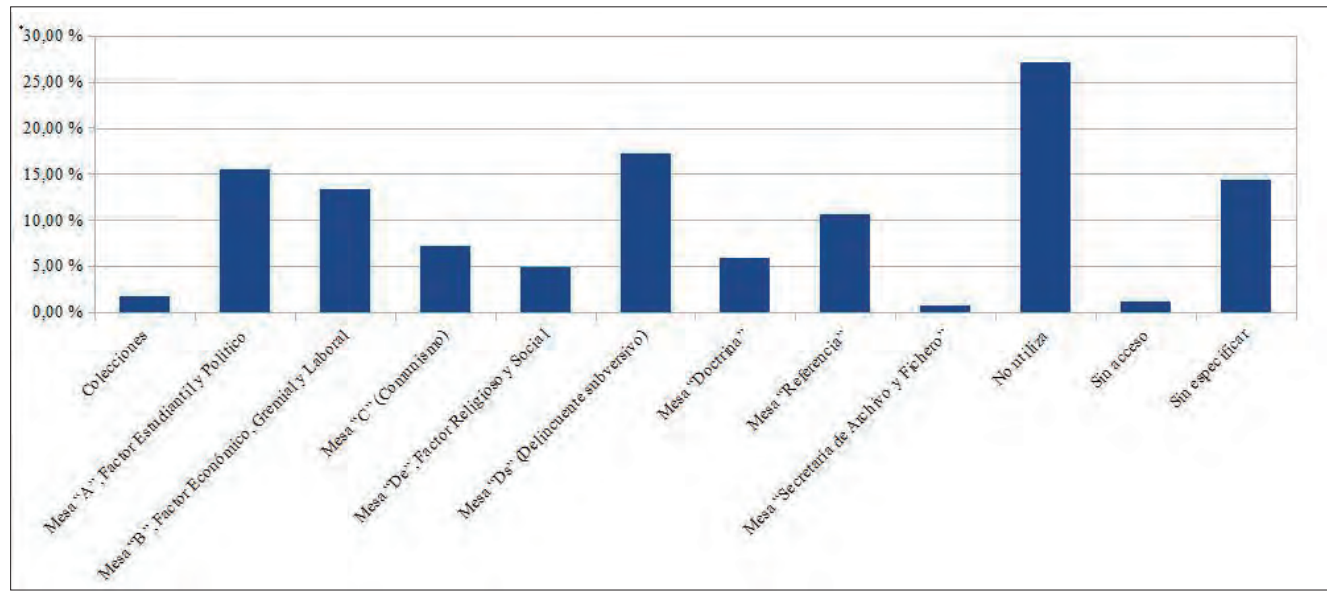

Fuente: Elaboración propia. 
Por último, respecto de los objetos de estudio de los artículos, hemos construido categorías inclusivas que abarcan los distintos temas abordados en las publicaciones. La clasificación realizada permitió construir los porcentajes de publicaciones que abordan dichos objetos de estudio (Gráfico 8).

Gráfico 8: Porcentaje de artículos por tema u objeto de estudio.

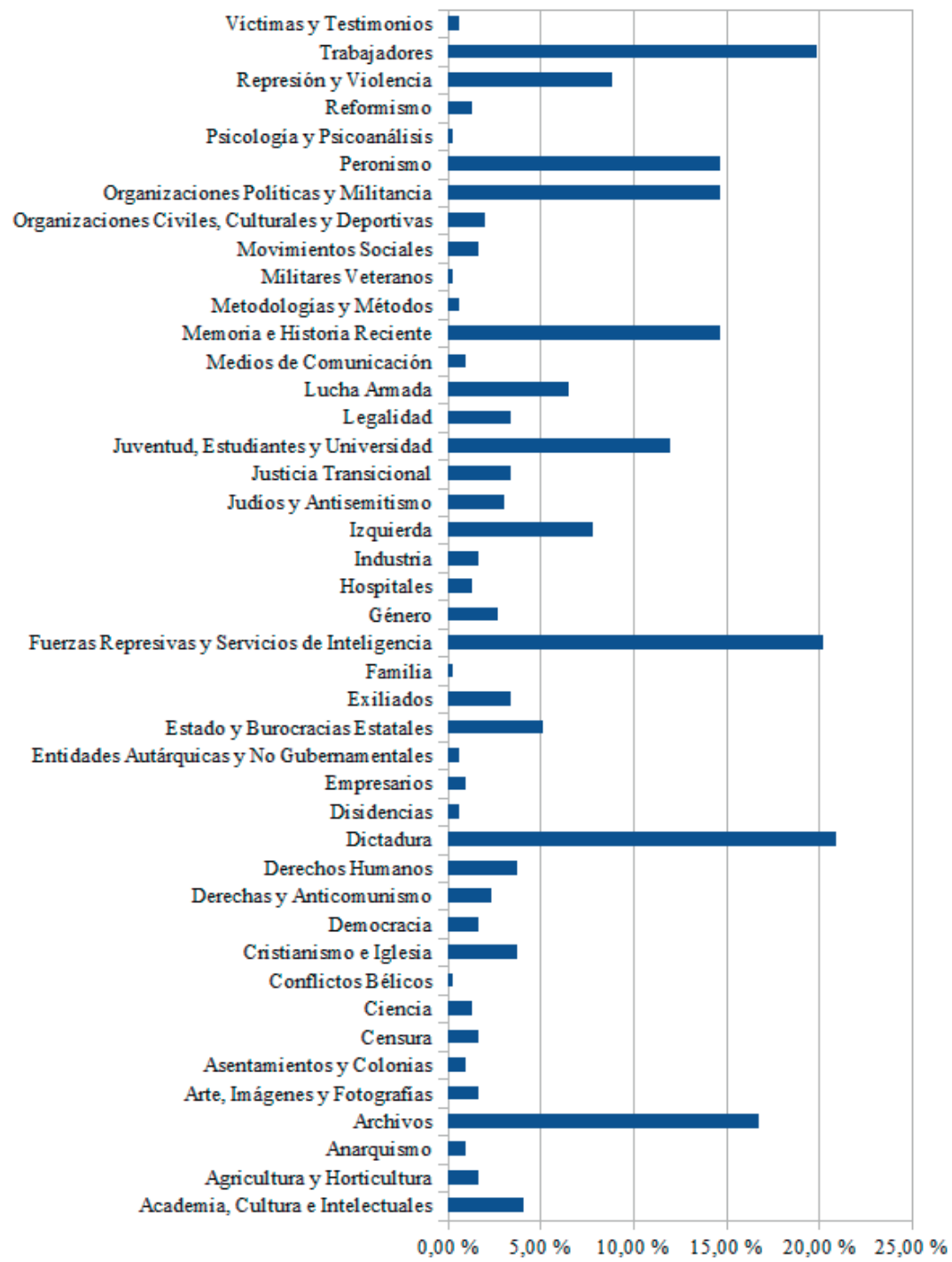

Fuente: Elaboración propia. 
Mediante la construcción de una matriz que clasifica las relaciones entre los artículos científicos y los temas u objetos de estudio, y su carga en el programa de análisis de redes sociales Visone 2.17, hemos elaborado una topografía que muestra la distribución de los artículos según los principales objetos de estudio (Gráfico 9). ${ }^{15}$

Gráfico 9: Red de artículos según objeto de estudio.

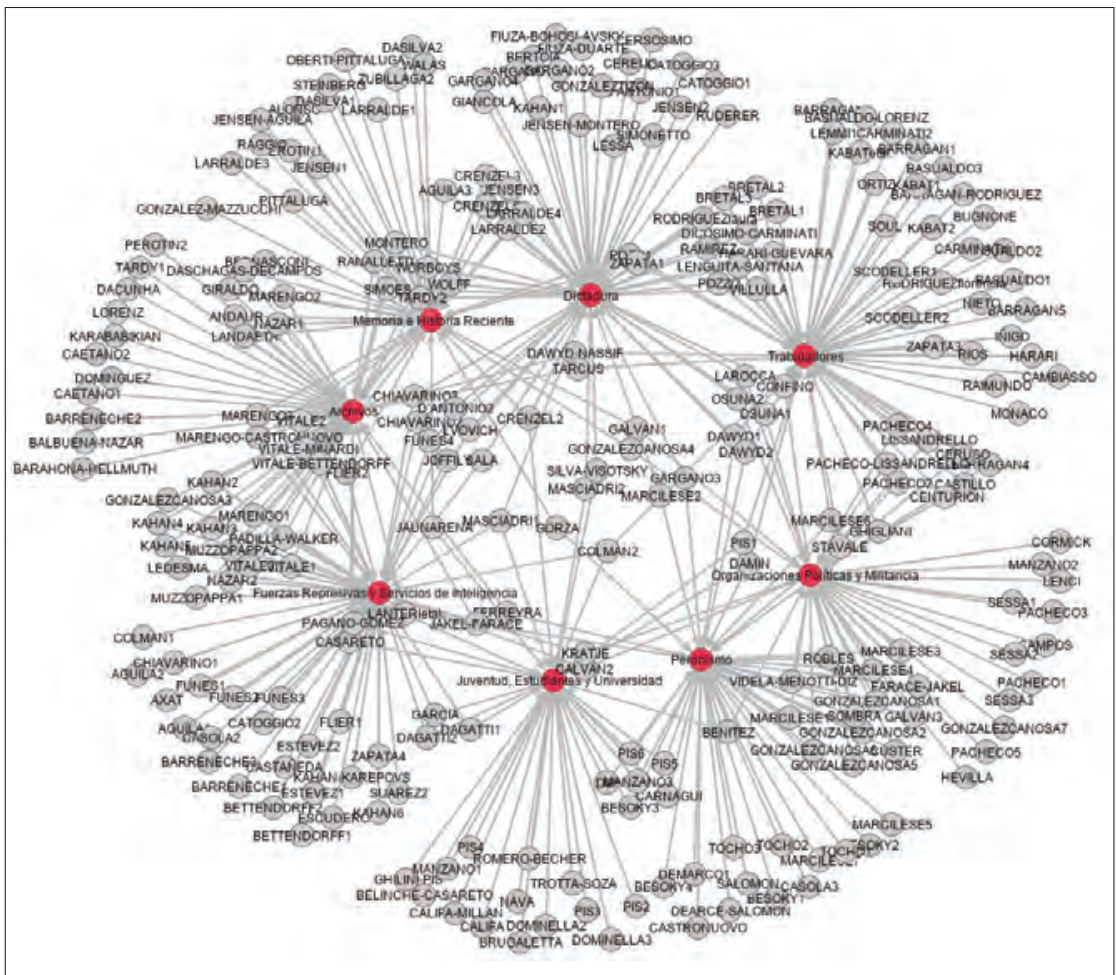

Fuente: Elaboración propia.

Según se puede observar, el gráfico posee una zona central y dos "cordones" en los que se ordena la distribución de los artículos según los objetos de estudio. Los artículos constituyen subconjuntos según su asociación a uno

15 Hemos seleccionado los principales objetos de estudio o temas abordados en el corpus (archivos, dictadura, fuerzas represivas, juventud, memoria, organizaciones políticas, peronismo, trabajadores) para construir un gráfico más simplificado y permitir una lectura más clara. 
o más de estos objetos. Una parte de estos subconjuntos están relacionados a uno sólo de los principales objetos de estudio (segundo cordón). Sin embargo, también se pueden distinguir subconjuntos que representan zonas de articulación temática (zona central y primer cordón).

La construcción de una segunda topografía permite expresar las conexiones entre los artículos científicos y la proveniencia de la documentación del archivo (Gráfico 10). En esta segunda red se visualizan subconjuntos de artículos agrupados según la proveniencia de la documentación (mesas), pudiéndose delimitar claramente tres subconjuntos asociados respectivamente a la Mesa "A" (Factor Político y Estudiantil), a la Mesa "B" (Factor Económico, Gremial y Laboral) y a la Mesa "Ds" (Delincuente subversivo, Factor Policial y Operacional, Carpetas Daños y Material Bélico).

Gráfico 10: Red de artículos según proveniencia de la documentación.

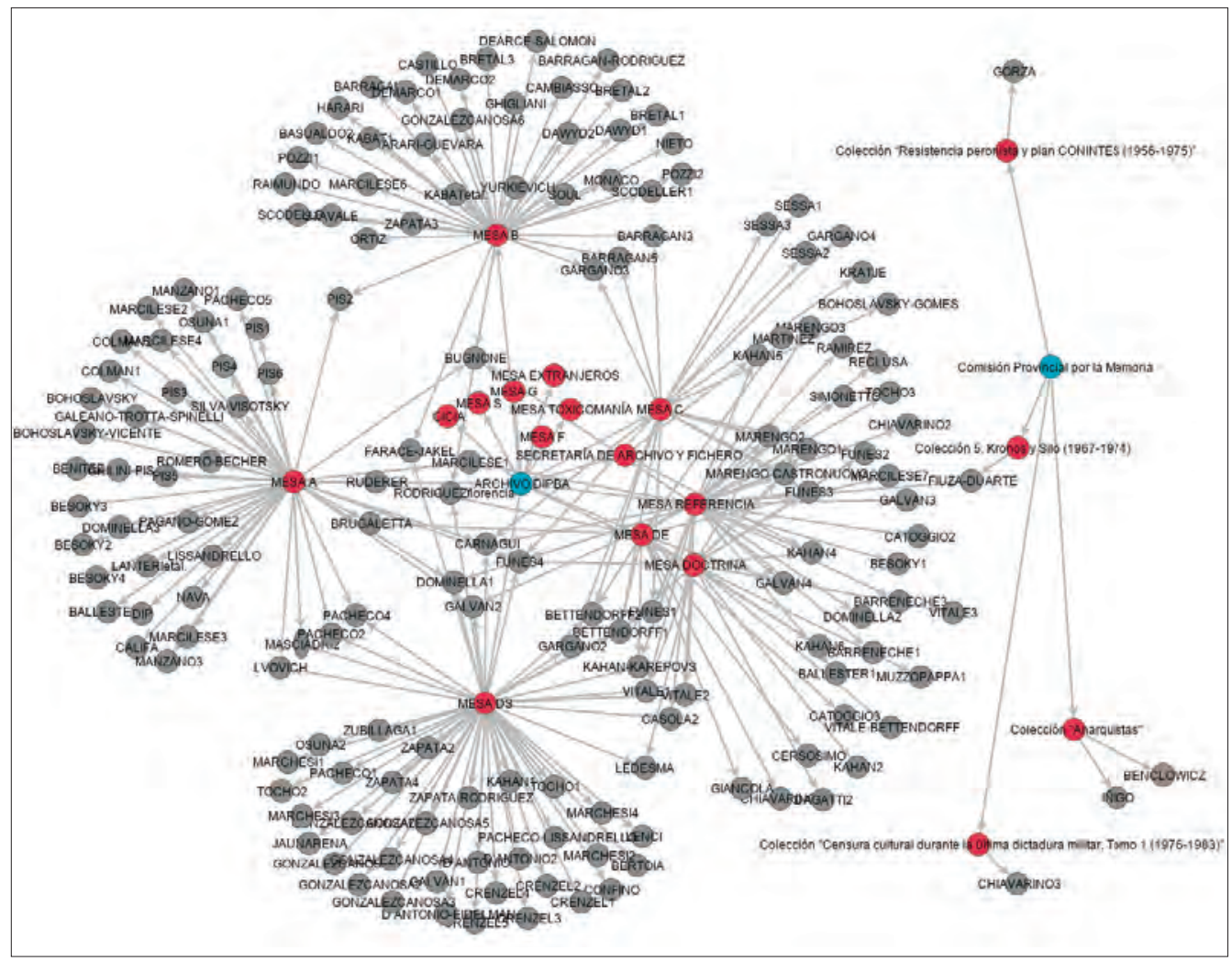

Fuente: Elaboración propia. 
Por otro lado, las Mesas "C" (Comunismo), "De" (Factor Social y Religioso), "Doctrina", "Referencia" y "Secretaría de Archivo y Fichero" se encuentran situadas en una misma zona de la red, dado que poseen un mayor grado de interconexiones relativas. En otras palabras, los artículos que han usado documentación de alguna de las mesas de este grupo parecen haber utilizado material de las demás mesas del mismo grupo en una proporción mayor que los subconjuntos de artículos asociados a las Mesas "A", "B" o "Ds" respecto de cualquiera de las demás mesas.

Mediante el programa de análisis estadístico JASP 0.11.1 hemos calculado las correlaciones entre el uso de las mesas del archivo por parte de los artículos del corpus y los principales objetos de estudio abordados por estos. Para esto, hemos importado en dicho programa una matriz binaria que indica, para cada artículo, información relativa a la proveniencia de la documentación del archivo (mesas) y al abordaje de distintos objetos de estudio. La siguiente matriz de correlaciones presenta los valores de correlación de Pearson calculados a partir de dicho procedimiento ${ }^{16}$.

Tabla 1: Valores de correlación de Pearson (mesas por objetos de estudio).

\begin{tabular}{|c|c|c|c|c|c|c|c|c|c|}
\hline \multicolumn{10}{|c|}{ Tabla I } \\
\hline \multicolumn{10}{|c|}{ Valores de correlación de Pearson (mesas por objetos de estudio) } \\
\hline & & Mesa "A" & Mesa "B" & Mesa "C" & Mesa "De" & Mesa "Ds" & \begin{tabular}{|l} 
Mesa \\
Referencia \\
\end{tabular} & $\begin{array}{l}\text { Mesa } \\
\text { Doctrina }\end{array}$ & $\begin{array}{l}\text { Secretaría } \\
\text { de Archivo } \\
\text { y Fichero }\end{array}$ \\
\hline \multirow{2}{*}{ Archivos } & Pearson's $\mathrm{r}$ & -0.105 & -0.178 & 0.069 & -0.098 & -0.042 & 0.264 & 0.631 & 0.338 \\
\hline & p-value & 0.177 & 0.021 & 0.377 & 0.207 & 0.591 & $<.001$ & $<.001$ & $<.001$ \\
\hline \multirow{2}{*}{ Dictadura } & Pearson's r & -0.079 & 0.030 & -0.008 & 0.110 & 0.069 & -0.093 & -0.124 & -0.056 \\
\hline & p-value & 0.311 & 0.696 & 0.923 & 0.154 & 0.376 & 0.231 & 0.111 & 0.468 \\
\hline \multirow{2}{*}{$\begin{array}{c}\text { Fuerzas Represivas y Servicios } \\
\text { de Inteligencin }\end{array}$} & Pearson's r & -0.102 & -0.297 & 0.197 & 0.094 & 0.069 & 0.366 & 0.573 & 0.203 \\
\hline & p-value & 0.188 & $<.001$ & 0.011 & 0.224 & 0.375 & $<.001$ & $<.001$ & 0.008 \\
\hline \multirow{2}{*}{$\begin{array}{c}\text { Juventud, E studiantes y } \\
\text { Universidad }\end{array}$} & Pearson's r & 0.577 & -0.202 & -0.111 & -0.073 & -0.153 & -0.125 & -0.093 & -0.048 \\
\hline & p-value & $<.001$ & 0.009 & 0.153 & 0.345 & 0.048 & 0.108 & 0.230 & 0.536 \\
\hline \multirow{2}{*}{ Memoria e Historia Reciente } & Pearson's r & \begin{tabular}{|c|} 
\\
\end{tabular} & -0.106 & 0.031 & -0.087 & 0.143 & 0.092 & 0.198 & -0.032 \\
\hline & p-value & 0.023 & 0.170 & 0.689 & 0.260 & 0.064 & 0.236 & 0.010 & 0.683 \\
\hline \multirow{2}{*}{$\begin{array}{c}\text { Organizaciones Políticas y } \\
\text { Militancia }\end{array}$} & Pearson's r & 0.059 & -0.080 & 0.015 & -0.143 & 0.179 & -0.108 & -0.160 & -0.052 \\
\hline & p-value & 0.449 & 0.304 & 0.850 & 0.064 & 0.020 & 0.165 & 0.039 & 0.501 \\
\hline \multirow{2}{*}{ Peronismo } & Pearson's r & 0.117 & 0.092 & -0.085 & -0.091 & -0.095 & -0.035 & -0.163 & -0.053 \\
\hline & p-value & 0.130 & 0.234 & 0.275 & 0.239 & 0.219 & 0.649 & 0.035 & 0.493 \\
\hline \multirow{2}{*}{ Trabajadores } & Pearson's r & -0.134 & 0.714 & -0.155 & -0.163 & -0.239 & -0.184 & -0.181 & -0.059 \\
\hline & p-value & 0.083 & $<.001$ & 0.045 & 0.035 & 0.002 & 0.017 & 0.019 & 0.445 \\
\hline
\end{tabular}

Fuente: Elaboración propia.

16 Los valores de correlación de Pearson (Pearson's r $r$ ) miden el grado de relación lineal entre cada par de elementos o variables consideradas. Para esto utilizamos la siguiente escala: -1 (correlación negativa grande y perfecta), $-0,9$ a $-0,99$ (correlación negativa muy alta), $-0,7$ a $-0,89$ (correlación negativa alta), $-0,4$ a $-0,69$ (correlación negativa moderada), $-0,2$ a $-0,39$ (correlación negativa baja), $-0,01$ a - 0,19 (correlación negativa muy baja), 0 (correlación nula), 0,01 a 0,19 (correlación positiva muy baja), 0,2 a 0,39 (correlación positiva baja), 0,4 a 0,69 (correlación positiva moderada), 0,7 a 0,89 (correlación positiva alta), 0,9 a 0,99 (correlación positiva muy alta) y 1 (correlación positiva grande y perfecta). 
Hemos registrado cuatro valores que representan grados de correlación que nos parecieron significativos: Mesa "B"-trabajadores (0,714), Mesa Doctrinaarchivos $(0,631)$, Mesa Doctrina-fuerzas represivas y servicios de inteligencia $(0,573)$ y Mesa "A"-juventud, estudiantes y universidad (0,577). Esto significa que la mayor parte de los artículos que se han dedicado a estudiar los cuatro temas mencionados han usado documentos de las mesas correspondientes, y que la mayor parte de los artículos que han utilizado documentos de estas mesas han abordado los objetos de estudio indicados.

Para interpretar estos valores, es necesario recordar que las mesas de este archivo organizan documentación clasificada según criterios temáticos definidos históricamente por la DIPBA (denominados "factores"). En este contexto, la Mesa "A" contiene los factores Estudiantil y Político, la Mesa "B" abarca los factores Económico, Gremial y Laboral, en tanto que la Mesa "Doctrina" agrupa fundamentalmente material reglamentario e institucional. Los cuatro valores mencionados parecen indicar que los usos de la documentación han respetado la organización temática original de la documentación del archivo, al menos para el caso de los artículos que han abordado estos objetos de estudio. Cabe señalar que esto no se observa en otras correlaciones, lo que es significativo para el caso de la relación entre la Mesa "A" y el objeto organizaciones políticas y militancia, dado que dicha mesa contiene el factor político. La diferencia observada puede obedecer a diversas variables -entre las que es necesario incluir posibles defectos en los criterios de clasificación manejados en este trabajo-, sin embargo nos gustaría adelantar una hipótesis posible. Y es que a pesar de que la información sobre las organizaciones políticas se concentra en la Mesa "A", factor Político, existiría sin embargo una dispersión, en todo el archivo de la DIPBA, de la presencia y las menciones a las distintas organizaciones: en la Mesa "B", dadas las articulaciones entre política y mundo del trabajo; en las mesas "C" y "Ds", por características que hacen a la construcción histórica de los objetos "comunista" o "delincuente subversivo" como enemigo interno y su relación con las organizaciones políticas, entre otras cuestiones posibles.

Esta primera aproximación, estadística y topográfica, a los usos del archivo de la DIPBA en el ámbito científico-académico permite especificar, aunque sea de modo superficial, cómo los artículos científicos que han utilizado documentación proveniente de dicho acervo se constituyen en prácticas de marcación que conectan al archivo con la producción de representaciones sobre diversos temas ligados a la historia reciente. En otras palabras, puede observarse cómo se despliega la circulación de la documentación en relación a sus usos en el ámbito científico-académico. Se trata de una modalidad de circulación centrífuga, que responde a una jerarquía de intereses temáticos definida por las 
condiciones de las distintas áreas disciplinares que han hecho uso del archivo. En este contexto, los estudios históricos e historiográficos $-\mathrm{y}$ en particular, la historia reciente- son los que más han pesado en dicha definición. En el siguiente apartado nos abocaremos a examinar, en la discursividad de los artículos científicos, cómo se construyen las relaciones entre las instancias de enunciación de los artículos y la documentación con el objetivo de indagar ciertos aspectos del dispositivo de enunciación histórico e historiográfico en la producción de representaciones controladas sobre el pasado reciente.

\section{MODOS DE USO Y LECTURA DEL ARCHIVO DE LA DIPBA EN LOS ESTUDIOS DE HISTORIA RECIENTE}

El objetivo en esta parte del artículo es analizar, en el discurso de una serie de artículos científicos que han utilizado documentación proveniente del archivo de la DIPBA, cómo se presenta la relación entre los investigadores y la documentación del archivo en el trabajo de producción de representaciones sobre el pasado reciente. Partimos de la hipótesis de que esa relación, según se pone en juego en la discursividad de los artículos, forma parte de un dispositivo enunciativo que apunta a legitimar y tornar eficaz la producción de "objetividad" en el ámbito de la historia reciente, constituyendo al pasado y al archivo como objetos de indagación.

El análisis de estas relaciones y procesos interesa por una serie de factores. En primer lugar, por el carácter reciente y problemático de la consolidación de este ámbito de estudio en Argentina. Como indica Laura Luciani, "la apertura del campo historiográfico hacia la temática no fue lineal ni progresiva, y tempranamente cosechó críticas" (Luciani 201). Si bien el foco de las mismas fue variando a lo largo del tiempo, pueden señalarse principalmente cuestionamientos a las posibilidades mismas de la investigación histórica del pasado reciente, por una mentada falta de documentación para analizar estas temáticas -que la apertura del archivo de la DIPBA, entre otros procesos, permitió comenzar a desmitificar-, o por elementos que hacen a la naturaleza de la relación con el pasado sostenida mayoritariamente por la historiografía académica. ${ }^{17}$ Asimismo, se ha cuestionado el carácter mismo de la producción académica sobre el pasado reciente, tachada de "política" por figuras significativas del campo disciplinar

17 Esta, "guiada por los propósitos científicos de «objetividad», exige «distancia» y «perspectiva» con el tema de investigación para lo cual debe considerarlo fijado, terminado y, a partir de allí, poder producir un acercamiento gradual a lo pasado" (Flier y Kahan 172-173). 
como Luis Alberto Romero, si bien -según sostiene Gabriela Águila- la mayoría de las veces este tipo de críticas no se hicieron públicamente sino "permaneciendo en sordina o reservadas a reuniones académicas" (Águila, "La historia" 66). Si los debates sobre el ámbito de la historia reciente al interior del campo disciplinar de la historia "propiciaron estrategias propias del ámbito académico que legitimaron su existencia" (Luciani 201), estas quizás puedan ser reconocidas en la discursividad de las publicaciones especializadas.

En este sentido, diversos autores han destacado la particular relación entre la dimensión ético-política y la científico-académica en los estudios de historia reciente, como "marca de origen" que "constituye y moldea toda la producción en la región" (Franco 178; Luciani 211). Creemos que esta doble inscripción puede examinarse en los artículos estudiados, y que parte de su especificidad podría ser reconocida en la relación, construida discursivamente, entre los investigadores y la documentación proveniente de "archivos de la represión" como el de la DIPBA.

Nuestro estudio puede ser situado en el conjunto de investigaciones enfocadas en la comprensión de los modos en que es posible producir "verdad", "objetividad" o "representaciones" aceptadas en una comunidad específica: la comunidad científica. Se trata, en primer lugar, de examinar las asociaciones entre sujetos y objetos que caracterizan el funcionamiento del archivo en el contexto de la producción de representaciones sobre el pasado, y en segundo lugar, de analizar los modos en que en estas se despliega una forma de "constructividad discursiva", que es

conversacional e instrumental a la vez: las palabras y los instrumentos se montan recíprocamente en una secuencia generalmente significativa que es capaz de ser constructiva (a partir de una subjetividad que plantea el objeto) y al mismo tiempo perfectamente objetiva (desde el punto de vista del reconocimiento de un funcionamiento objetivo del mundo). (Fabbri, El giro 104)

En este contexto, las apropiaciones y usos de los archivos en el ámbito científico-académico participan de la conformación de estos acervos en fuentes documentales y objetos de estudio. Desde el punto de vista de su modo de existencia, un archivo es una unidad compleja que ingresa en una red de conexiones con otros artefactos y con seres vivos, que componen sus condiciones específicas de funcionamiento. Por su parte, las "funciones" de un archivo como tecnología intelectual son entendidas aquí como efectos, en el sentido de que rebasan cualquier tipo de intencionalidad o estado mental que pretenda definirlas de una vez y para siempre. De hecho, 
las trayectorias históricas que siguen muchas tecnologías son imprevisibles no sólo para diseñadores y usuarios, sino que a veces incluso se vuelven contra ellos, causando, por ejemplo, "efectos de venganza": consecuencias no intencionadas que superan los beneficios previstos. (Vaccari 3)

Esto es particularmente claro en el caso de los archivos de la represión, elementos constitutivos de la represión legal e ilegal en la historia reciente cuyo efecto jurídico hoy impacta como "efecto boomerang" (Keck y Sikkink 93) contra los propios represores.

En los estudios históricos, el archivo puede ser comprendido como un objeto, una unidad compleja por medio de la cual investigadores y documentación se asocian para producir representaciones sobre el pasado reciente, las cuales son puestas en discusión mediante su presentación en determinados circuitos convencionales (revistas, congresos, conferencias, etcétera) para ser finalmente aceptadas - o rechazadas- en el seno de la comunidad científica. ${ }^{18}$

Nuestro estudio se enmarca en la concepción del análisis del discurso como práctica interpretativa (Arnoux), y tiene como objetivo examinar cómo se inscribe la presentación discursiva de la relación entre los investigadores y las fuentes del archivo en el dispositivo de enunciación de los estudios de historia reciente, así como la generación de efectos enunciativos y discursivos a partir de los usos del archivo. El análisis se aboca, entonces, a indagar la inscripción y especificación discursiva de las instancias de enunciación de los artículos - la construcción, a partir de marcas propias de la redacción científica, de un enunciador y un enunciatario asociados al género "artículo de investigación científica"-, así como la objetivación discursiva de los documentos del archivo -su constitución como "objeto de estudio" o como "fuente"-, y la puesta en relación entre las instancias de enunciación y la documentación.

Para este análisis, hemos seleccionado artículos de investigación científica inscriptos en las disciplinas históricas que han utilizado documentación del archivo de la DIPBA como fuente u objeto de estudio (subconjunto que representa un 50\%

18 En el ámbito de los estudios históricos en Argentina, este recorrido posee su propia historicidad: se instituye y fortalece a comienzos de los años ochenta, durante la transición democrática, cuando "los estudios históricos debían liberarse de la politización con la que 'cargaban' y construir un ‘campo académico' especializado centrado en la figura del profesional en desmedro de la del intelectual. 'La 'despolitización' - liberar a la historiografía de su contexto político- se cifró en el respeto por ciertos procedimientos que abarcaban desde el trabajo con fuentes primarias hasta los circuitos de crítica y aprobación de papers' (Pittaluga, 2007, p. 136)" (Raina 113). 
del corpus total de artículos). De este recorte de 146 artículos se han seleccionado diez al azar: cinco están asociados al uso del archivo como fuente, y los restantes, a su uso como objeto de estudio. Los artículos son los siguientes: ${ }^{19}$

- Barragán, Ivonne. "Mujeres trabajadoras y delegadas sindicales en un astillero de la Armada Argentina. Astillero Río Santiago (1973-1978)". Nomadias, no. 20, 2015, pp. 227-248. (BARRAGAN4).

- Casola, Natalia Laura. "Los indeseables. El exilio chileno en la mirada de la DIPBA (1973-1983)". Clepsidra. Revista Interdisciplinaria de Estudios sobre Memoria, vol. 4, no. 7, 2017, pp. 50-67. (CASOLA2).

- D’Antonio, Débora Carina. "Derechos humanos y estrategias de la oposición bajo la dictadura militar argentina". Tensões Mundiais, vol. 6, no. 11, 2010, pp. 153-178. (D’ANTONIO1).

- Funes, Patricia. "Ingenieros del alma. Los informes sobre canción popular, ensayo y Ciencias Sociales de los Servicios de Inteligencia de la dictadura militar argentina sobre América Latina". Varia historia, vol. 23, no. 38, 2007, pp. 418-437. (FUNES3).

- Gárgano, Cecilia. "Experimentación científica, genética aviar y dictadura militar en el Instituto Nacional de Tecnología Agropecuaria (19561976)". Mundo agrario, vol. 15, no. 28, 2014, pp. 1-31. (GARGANO2).

- Kahan, Emmanuel Nicolás. "Unos pocos peligros sensatos. La Dirección de Inteligencia de la Policía de la Provincia de Buenos Aires frente a las instituciones judías de la ciudad de La Plata”. Aletheia, vol. 1, no. 1, 2010, pp. 1-8. (KAHAN5).

- Marengo, María Eugenia, y Sabrina Castronuovo. El archivo policial como espacio de memoria: un sondeo por el ex archivo de la DIPPBA. Revista Electrónica de Fuentes y Archivos, vol. 6, no. 6, 2015, pp. 106-125. (MARENGO-CASTRONUOVO).

- Pacheco, Julieta. "La izquierda peronista y su inserción en el movimiento obrero". Revista Latino-americana de Estudos do Trabalho, vol. 19, no. 32, 2014, pp. 157-184. (PACHECO4).

- Pacheco, Julieta, y Guido Lissandrello. "Montoneros y el PRT-ERP: una propuesta comparativa a partir del análisis de sus posiciones frente al movimiento obrero (1973-1976)". Amérique Latine Histoire et Mémoire. Les Cahiers ALHIM, no. 26, 2013. (PACHECO-LISSANDRELLO).

- Zapata, Ana Belén. "Violencia parapolicial en Bahía Blanca, 1974-1976. Delgados límites entre lo institucional y lo ilegal en la lucha contra la

19 Entre paréntesis se incluyen los nombres utilizados para la clasificación (ver Tabla 2). 
"subversión apátrida"”. Anos 90, vol. 19, no. 35, 2012, pp. 111-140. (ZAPATA 4).

Tabla 2: Corpus de artículos seleccionados para el análisis.

\begin{tabular}{|c|c|c|c|c|}
\hline \multicolumn{5}{|c|}{ Tabla II } \\
\hline \multicolumn{5}{|c|}{ Corpus de artículos seleccion ados para el análisis } \\
\hline Artículo & Tipo de uso del archiv o & Objetos de estudio & Cortes cronológicos & $\begin{array}{c}\text { Proveniencia del } \\
\text { material docum ental }\end{array}$ \\
\hline BARRAGAN4 & fuente & $\begin{array}{c}\text { Género, Organizaciones } \\
\text { Politicas yMilitancia, } \\
\text { Trabajadores } \\
\end{array}$ & $1970-1975,1976-1983$ & Mesa "B" \\
\hline D'ANTONIO1 & fuente & Derechos Humanos, Dictadura & $1976-1983$ & Mesa "Ds", Carpeta Varios \\
\hline CASOLA2 & objeto de estudio & \begin{tabular}{|c|} 
Exiliados, Fuerzas Represivas \\
y Servicios de Intel igencia
\end{tabular} & $1970-1975,1976-1983$ & $\begin{array}{c}\text { Mesa "Ds", Carpeta Varios } \\
\text { Mesa Referencia }\end{array}$ \\
\hline FUNES3 & objeto de estudio & $\begin{array}{c}\text { Academia, Cultura e } \\
\text { Intelectuales, Fuerzas } \\
\text { Represivas y Servicios de } \\
\text { Inteligencia }\end{array}$ & $1976-1983$ & $\begin{array}{c}\text { Mesa "C", Carpeta Varios } \\
\text { Mesa Doctrina } \\
\text { Mesa Referencia }\end{array}$ \\
\hline GARGANO2 & fuente & Ciencia, Dictadura & $\begin{array}{c}1956-1960,1960-1970,1970- \\
1975,1976-1983\end{array}$ & $\begin{array}{l}\text { Mesa "C", Carpeta Varios } \\
\text { Mesa "Ds", Carpeta Varios }\end{array}$ \\
\hline KAHAN5 & objeto de estudio & $\begin{array}{c}\text { Archivos, Fuerzas Represivas } \\
\text { y Servicios de Inteligencia, } \\
\text { Judios y Antis emitismo }\end{array}$ & $\begin{array}{c}1956-1960,1960-1970,1970- \\
1975,1976-1983\end{array}$ & $\begin{array}{c}\text { Mesa Referencia } \\
\text { Mesa Secretaria de Archivo y } \\
\text { Fichero }\end{array}$ \\
\hline $\begin{array}{l}\text { MARENGO- } \\
\text { CASTRONUOVO }\end{array}$ & objeto de estudio & $\begin{array}{l}\text { Archivos, Fuerzas Represivas } \\
\text { y Servicios de Inteligencia, } \\
\text { Memoria e Historia Reciente }\end{array}$ & \begin{tabular}{|} 
1930-1955, 1956-1960, 1960- \\
1970, 1970-1975, 1976-1983, \\
1984-1998, 1998-Actualidad
\end{tabular} & $\begin{array}{c}\text { Mesa "C", Carpeta Varios } \\
\text { Mesa Doctrina } \\
\text { Mesa Referencia, Carpeta } \\
\text { Decretos Leyes y } \\
\text { Disposiciones }\end{array}$ \\
\hline $\mathrm{PACHECO} 4$ & fuente & $\begin{array}{l}\text { Organizaciones Politicas y } \\
\text { Militancia, Trabajadores }\end{array}$ & $1970-1975,1976-1983$ & $\begin{array}{c}\text { Mesa "A" } \\
\text { Mesa "Ds", Carpeta Material } \\
\text { Bélico }\end{array}$ \\
\hline $\begin{array}{c}\text { PACHECO } \\
\text { LISSANDRELLO }\end{array}$ & fuente & $\begin{array}{c}\text { Lucha armada, Organizaciones } \\
\text { Politicas yMilitancia, } \\
\text { Trabajadores }\end{array}$ & $1970-1975,1976-1983$ & $\begin{array}{c}\text { Mesa "Ds", Carpeta Material } \\
\text { Bélico }\end{array}$ \\
\hline ZAPATA4 & objeto de estudio & $\begin{array}{l}\text { Fuerzas Represivas y } \\
\text { Servicios de Inteligencia, } \\
\text { Represión y Violencia }\end{array}$ & $1970-1975,1976-1983$ & Mesa "Ds", Carpeta Varios \\
\hline
\end{tabular}

Fuente: Elaboración propia.

\subsection{El dispositivo de enunciación en los estudios de historia reciente}

Como hemos señalado, la producción de hechos científicos -0 , en nuestro caso, de representaciones consensuadas sobre el pasado reciente- involucra la creación de artículos para su evaluación y publicación en determinados circuitos convencionales. Algunos autores sostienen que este género, el artículo de investigación científica, "es uno de los que, por sus características discursivas 
particulares, puede reunir mayor evidencia lingüística sobre las actitudes, valores, creencias, grados de obligación y compromiso de quienes producen los textos" (Briceño Velazco 78). Las producciones asociadas a dicho género pueden ser consideradas como textos de naturaleza expositivo-argumentativa con gran peso de la argumentación, dado que "el autor ofrece los resultados originales de su revisión teórica o su investigación científica original, de sus hallazgos, con el propósito de conseguir la aprobación y la validación de la comunidad científica universal a la que pertenece" (Regueiro y Sáez 79).

A nivel compositivo, los artículos académicos poseen una estructura normalizada que consiste en el título del artículo seguido del nombre de los autores, un resumen del texto y un esquema denominado IMRaD (introducción, materiales y métodos, resultados y discusión, que puede variar relativamente según el área disciplinar). Según se ha señalado a partir del examen de sus variaciones en disciplinas específicas, "la organización retórica de los artículos de investigación se ve condicionada por las convenciones académicas y por las expectativas de las comunidades discursivas específicas" (Sánchez-Upegui 25), lo que involucra contextualizar la situación comunicativa en la que se inscriben.

En todo caso, como género vinculado al tipo de discurso científico, el artículo de investigación pone en juego marcas de redacción que involucran, entre otras, la configuración de un marco enunciativo específico ${ }^{20}$ : un enunciador y un enunciatario "científicos" que entablan relaciones particulares en una temporalidad definida por la estructura genérica del artículo (introducción, problema, hipótesis, análisis y conclusiones) y en una espacialidad propia que involucra distintos grados de desarrollo de la puesta en escena enunciativa. Las modalidades de redacción científica remiten a tradiciones o estilos variables que presentan distintos grados de manifestación de la subjetividad en el lenguaje. Al respecto, María Marta García Negroni ha mostrado que dichas marcas permiten la configuración de ethé discursivos diferentes, ${ }^{21}$ variables según las disciplinas.

20 La noción de enunciación remite clásicamente al proceso de apropiación o puesta en funcionamiento de la lengua por un acto individual de utilización, y remite necesariamente a un sujeto, el sujeto de la enunciación, que está constituido por la articulación entre sujeto enunciador y sujeto enunciatario, por lo que se ha preferido "hablar de instancia de la enunciación para dar cuenta de los dos polos constitutivos de la enunciación" (Filinich 39). El sujeto de la enunciación es el yo-tú subyacente que corresponde al nivel enunciativo.

21 Tomado de la retórica antigua, el ethos (plural: ethé) refiere a "la imagen de sí que construye el locutor en su discurso para ejercer influencia sobre su alocutario" (Maingueneau y Charaudeau 246). En su discurso, el enunciador se otorga una posición institucional y marca su relación con un saber para legitimarse. La imagen construida por el enunciador es un efecto de discurso que se encuentra anclada en estereotipos culturales. Mediante esta operación, el enunciador se dota de una corporalidad y de un carácter cuyas características se vinculan a la situación de enunciación, 
Así,

la fuerte presencia de referencias semi-integradas y de citas textuales de los discursos de los otros miembros de la comunidad académica en los subcorpus de Historia y de Lingüística da cuenta de la importancia que, en estas disciplinas, revisten los textos previos como objetos de investigación y contribuyen a la constitución de un ethos preocupado por mostrar el conocimiento del universo disciplinar. (García Negroni 27)

Entre los elementos discursivos que proveen marcas de redacción científica, se pueden distinguir: a) marcadores de metadiscurso ${ }^{22}$ y metatexto, que atañen a las marcas de persona o auto-menciones que realiza el enunciador en el texto: estilo "personal" a partir del uso de la primera persona del plural con referencia genérica, del nosotros inclusivo, del nosotros de modestia o de la primera persona coincidente, o estilo "impersonal" o desagentivado a partir de estrategias de despersonalización como el uso de nominalizaciones, estructuras impersonales con infinitivo, metonimias o pasivas con "ser" y con "se" (García Negroni 12-14); a los marcadores relacionales de compromiso con el enunciatario o el auditorio; y a los comentarios que tematizan la estructura del texto científico (Salas Valdebenito 96-97); b) marcadores léxicos de categorización (nombres y verbos) y de calificación (adjetivos y adverbios) que remiten a un lenguaje formal o especializado, y a distintos campos semánticos temáticos; c) determinadas marcas de subjetividad, como el predominio de modalidades u operaciones de modalización de naturaleza epistémica y marcadores de evidencialidad, utilizados por los enunciadores para "calibrar el grado de probabilidad/certeza que otorgan a sus enunciados y presentar la evidencia que sustenta sus afirmaciones" (Ferrari 20), modos de citación y glosas metadiscursivas (García Negroni 16); d) elecciones de orden de palabras y de predicaciones, entre los que se pueden incluir construcciones causales y consecutivas, operadores de cohesión, coordinación paratáctica e hipotáctica, etcétera; e) el uso de documentación probatoria extrínseca como documentos adjuntos, estadísticas, testimonios, y

por lo que están afectadas por prescripciones del género discursivo, tal como sucede en el caso del discurso científico-académico.

22 "El metadiscurso o reflexividad del discurso (Mauranen, 2010) es un rasgo de la prosa académicacientífica que abarca tres aspectos (Ädel, 2006): 1) cómo los escritores científicos se refieren a sí mismos, 2) cómo se dirigen y se relacionan con su audiencia y 3) cómo se refieren a sus propios textos" (Salas Valdebenito 96). 
otros; f) la construcción explícita del intertexto mediante la puesta en juego de referencias bibliográficas y de fuentes, en articulación con citas o pasajes de carácter "informativo"; g) el uso de la enunciación histórica o desembragada, utilizada para narrar los acontecimientos pasados sin intervención del hablante (Maingueneau 118), entre otros.

Los artículos de nuestro corpus varían relativamente respecto de los marcadores de redacción científica utilizados. Las siguientes tablas presentan los resultados de la identificación y clasificación de los recursos según cuatro grupos de categorías: a) marcadores metadiscursivos y metatextuales, b) elecciones de categorización y calificación, c) transtextualidad y marcas de heterogeneidad mostrada (incluyendo construcción del intertexto, modalidades de citación, modalidades de comentario y reformulación, y presentación y calificación de la documentación del archivo de la DIPBA) y d) relaciones entre enunciación y relato histórico (Tablas 3, 4, 5 y 6).

Tabla 3: Marcadores metadiscursivos y metatextuales.

\begin{tabular}{|c|c|}
\hline \multirow{2}{*}{ Artículo } & Tabla III \\
\hline & Marcadores metadiscursivos y metatextuales \\
\hline BARRAGAN4 & $\begin{array}{l}\text {-Autorreferencias: Estilo personal ("nosotros" de modestia). También hay presencia de formas impersonales } \\
\text { (construcciones pasivas con "se", nominalizaciones y'o tercera persona). } \\
\text {-Marcadores de relación: Poca presencia. Construcciones de tercera persona con modalidades deónticas. } \\
\text {-Marcadores de metatex to: Presencia de marcadores que refieren al articulo global o particularmente. }\end{array}$ \\
\hline CASOLA2 & $\begin{array}{l}\text {-Autorreferencias: Recurrencia de formas personales ("nosotros" de modestia) e impersonales (construcciones } \\
\text { con "se", "ser", en tercera persona y con uso de infinitivo, entre otras). } \\
\text {-Marcadores de relación: "Nosotros" inclusivo con valor genérico o de nacionalidad, construcciones } \\
\text { impersonales o que reenvian a un conocimiento dóxico, y modalidades deónticas. } \\
\text {-Marcadores de metatexto: Se registran marcadores de metatex to con carácter global. }\end{array}$ \\
\hline D'ANTONIOI & $\begin{array}{l}\text {-Autorreferencias: Uso de formas personales ("nosotros" de modestia), y en menor medida, impersonales } \\
\text { (construcciones con "se" o en tercera persona). } \\
\text {-Marcadores de relación: Presencia de modalidades deónticas, construcciones impersonales asociadas a verbos } \\
\text { como "ver", y "nosotros" inclusivo genérico. } \\
\text {-Marcadores de metatexto: Existen algunos casos de referencias metatextruales implicitas. }\end{array}$ \\
\hline FUNE S3 & $\begin{array}{l}\text {-Autorreferencias: Predominan las formas personales ("nosotros" de modestia), también hay presencia de } \\
\text { formas impersonales (construcciones con "se" y tercera persona). } \\
\text {-Marcadores de relación: Formas impersonales y "nosotros" inclusivo. } \\
\text {-Marcadores de metatex to: Presencia de marcadores que refieren al discurso global o particularmente. }\end{array}$ \\
\hline GARGANO2 & $\begin{array}{l}\text {-Autorreferencias: Formas impersonales sobre todo en introducción y conclusiones (tercera persona, con "se", } \\
\text { pasiva sin agente, o con participio, gerundio o infinitivo). Ausencia de formas personales. } \\
\text {-Marcadores de relación: Poca presencia, sobre todo de modalidad deóntica. } \\
\text {-Marcadores de metatex to: Recurrencia de marcadores metatex tuales globales y particulares. }\end{array}$ \\
\hline KAHAN5 & $\begin{array}{l}\text {-Autorreferencias: Uso de formas impersonales (tercera persona, nominalizaciones, metonimia y voz pasiva sin } \\
\text { agente) y personales ("nosotros" de modestia y un caso de primera persona singular). } \\
\text {-Marcadores de relación: Uso del "nosotros" inclusivo genérico y de modalidades deónticas. } \\
\text {-Marcadores de metatex to: Presencia de marcadores que refieren al discurso global o particularmente. }\end{array}$ \\
\hline $\begin{array}{l}\text { MARE NG O- } \\
\text { CASTRO- } \\
\text { NUOVO }\end{array}$ & $\begin{array}{l}\text {-Autorreferencias: Formas impersonales (tercera persona, impersonal con "se", construcciones con infinitivo y } \\
\text { voz pasiva sin agente), y casos de formas personales ("nosotros" de modestia y coincidencia). } \\
\text { - Marcadores de relación: Construcciones impersonales asociadas a verbos como "comprender", que pueden ser } \\
\text { interpretadas como referencias a enunciador y enunciatario, uso de "nosotros" inclusivo normalmente con } \\
\text { referencia a nacionalidad, y modalidades deónticas. } \\
\text {-Marcadores de metatexto: Se recurre a referencias globales al articulo. }\end{array}$ \\
\hline PACHE & $\begin{array}{l}\text {-Autorreferencias: Formas personales ("nosotros" de modestia). Casos de formas impersonales con "se". } \\
\text {-Marcadores de relación: "Nosotros" inclusivo, con referencia nacional o genérica, y modalidad deóntica. } \\
\text {-Marcadores de metatex to: Presencia de marcadores que refieren al discurso global o particularmente. }\end{array}$ \\
\hline
\end{tabular}




\begin{tabular}{|c|l|}
\hline PACHE CO- & $\begin{array}{l}\text {-Autorreferencias: Formas impersonales (tercera persona y construcciones impersonales) y personales } \\
\text { LISSANDRE - }\end{array}$ \\
(nLOsotros" de modestia o coincidencia). & $\begin{array}{l}\text {-Marcadores de relación: Construcciones impersonales asociadas a verbos como "percibir" o "apreciar" que } \\
\text { pueden entenderse en términos genéricos, y por tanto, como marcadores de relación; "nosotros" inclusivo. } \\
\text {-Marcadores de metatexto: Presencia de marcadores que refieren al discurso global o particularmente. }\end{array}$ \\
\hline ZAPATA4 & $\begin{array}{l}\text {-Autorreferencias: Formas personales ("nosotros" de modestia y primera persona singular). Algunas formas } \\
\text { impersonales, en ciertos casos reenvian a elementos dóxicos. } \\
\text {-Marcadores de relación: Construcciones impersonales con "se", que por su carácter genérico y su asociación a } \\
\text { verbos como "interpretar" pueden tener un carácter relacional; "nosotros" inclusivo. } \\
\text {-Marcadores de metatexto: Presencia de referencias globales al articulo, en introducción y conclusiones. }\end{array}$ \\
\hline
\end{tabular}

Fuente: Elaboración propia.

Como puede observarse en la Tabla 3, todos los artículos exhiben marcadores metadiscursivos y metatextuales, si bien los estilos y recursos usados son variables. En el caso de las autorreferencias, registramos que el número de artículos en los que predominan las formas personales $-\mathrm{y}$, particularmente, el llamado "nosotros" de modestia- es mayor, lo que parece estar en concordancia con una determinada tradición de la escritura académica que, si bien utiliza ciertos recursos de desagentivación y despersonalización propios de ese tipo de redacción, reclama una clara delimitación de los aportes de las producciones científicas y el no abuso de la impersonalidad (Prieto Acosta 7). Salvo el artículo de Cecilia Gárgano -que solo utiliza formas impersonales-, el resto hace uso de ambos estilos, produciendo y regulando, a partir de estos recursos, los efectos de impersonalidad, objetividad y subjetividad. La presencia de marcadores de relación y referencias al enunciatario también es variable, así como los recursos utilizados (nosotros inclusivo, modalidad deóntica, marcadores de compromiso, formas dóxicas), si bien hay presencia de alguna de estas marcas en todos los artículos. En algunos casos, los marcadores de relación poseen un valor asociado a la nacionalidad -"en nuestro país" (Casola 51) - o manifiestan una inscripción afectiva -"la herencia de esa destrucción aún nos atraviesa" (Funes, "Ingenieros" 436)- o político-ideológica -"hoy en día se nos presenta como "natural' la defensa de estos derechos" (D'Antonio, "Derechos Humanos" 157)-. Asimismo, las referencias metatextuales varían, aunque la mayor parte de los artículos exhiben marcadores de carácter global -"este artículo"- y particular -"en la primera parte", "en las conclusiones"-. De esta forma, si bien su grado de construcción es variable, estos distintos recursos permiten el despliegue de una situación de enunciación ${ }^{23}$ específica del artículo de investigación científica.

23 La noción de escena de enunciación remite a la representación que un discurso hace de su propia situación enunciativa (Charaudeau y Maingueneau 221). 
Tabla 4: Elecciones de categorización y calificación.

\begin{tabular}{|c|c|}
\hline \multirow{2}{*}{ Artículo } & Tabla IV \\
\hline & $\begin{array}{l}\text { Elecciones de categorización y calificación } \\
\end{array}$ \\
\hline BARRAGAN4 & $\begin{array}{l}\text {-Campos semánticos temáticos: 1) el trabajo y la producción, 2) el género 'mujer', 3) la organización sindical y } \\
\text { politica en el ámbito laboral, 4) la represión durante la última dictadura, 5) el campo semántico de la violencia, 6) } \\
\text { las fuentes documentales y testimoniales y 7) las relaciones de parentesco. Además, se pueden registrar campos } \\
\text { asociados al género discursivo y al vocabulario conceptual. } \\
\text {-Se registran marcas del discurso de los Derechos Humanos y algunas marcas apreciativas. }\end{array}$ \\
\hline CASOLA2 & $\begin{array}{l}\text {-Campos semánticos temáticos: 1) los exiliados, 2) los servicios de inteligencia, la dictadura y las fuerzas } \\
\text { represivas, 3) el archivo de la DIPBA, 4) la organización politica. También hay campos asociados a las } \\
\text { condiciones espaciales y temporales, al género discursivo y al uso de vocabulario conceptual. } \\
\text {-Marcas evaluativas de carácter axiológico propias del campo discursivo de los Derechos Humanos. }\end{array}$ \\
\hline D'ANTONIOI & $\begin{array}{l}\text {-Campos semánticos temáticos: 1) Derechos Humanos, 2) la dictadura militar y las fuerzas represivas, 3) las } \\
\text { fuentes documentales, testimoniales y periodisticas, 4) la justicia. Campos asociados a las condiciones espaciales } \\
\text { y temporales, y al uso de vocabulario conceptual. } \\
\text {-Marcas axiológicas vinculadas al discurso de los Derechos Humanos, y marcas apreciativas. }\end{array}$ \\
\hline FUNE S3 & $\begin{array}{l}\text {-Campos semánticos temáticos: 1) la represión y las fuerzas de seguridad, 2) el archivo de la DIPBA, 3) la } \\
\text { academia, 4) la cultura y 5) léxico referido a la izquierda (normalmente reproducido por la DIPBA). Campos } \\
\text { asociados a las condiciones espaciales, al género discursivo, y al vocabulario disciplinar. } \\
\text {-Se registran marcas evaluativas de carácter axiológico y marcas apreciativas. }\end{array}$ \\
\hline GARGANO2 & $\begin{array}{l}\text {-Campos semánticos temáticos: 1) la investigación y producción agropecuaria, 2) la dictadura militar y la } \\
\text { represión, 3) las fuentes documentales y testimoniales y 4) el mundo del trabajo. Campos asociados a las } \\
\text { condiciones espaciales y temporales, al género discursivo y al uso de vocabulario conceptual. } \\
\text {-Presencia de algunas marcas evaluativas de carácter axiológico. }\end{array}$ \\
\hline KAHAN5 & $\begin{array}{l}\text {-Campos semánticos temáticos: 1) el archivo de la DIPBA, 2) la DIPBA como servicio de inteligencia, asociado } \\
\text { al campo semántico de la represión, 3) los sujetos vigilados, como campo más disperso, y 4) el campo } \\
\text { discursivo de los Derechos Humanos. Campos vinculados a las condiciones espaciales y temporales, al género } \\
\text { discursivo, y al uso de un vocabulario conceptual especializado. } \\
\text { - Marcas evaluativas de carácter axiológico, vinculadas al campo discursivo de los Derechos Humanos, y } \\
\text { presencia de algunas marcas apreciativas. }\end{array}$ \\
\hline $\begin{array}{l}\text { MARE NG O- } \\
\text { CASTRO- } \\
\text { NUOVO }\end{array}$ & $\begin{array}{l}\text {-Campos semánticos temáticos: 1) las fuentes documentales y testimoniales, 2) la represión y la inteligencia } \\
\text { policial, 3) la memoria y los Derechos Humanos, 4) la politica, 5) las personas y la subjetividad. Campos } \\
\text { asociados a las condiciones espaciales y temporales, al género discursivo y al vocabulario conceptual. }\end{array}$ \\
\hline & $\begin{array}{l}\text {-Campos semánticos temáticos: 1) el mundo laboral, 2) la organización sindical y politica, 3) las fuerzas } \\
\text { represivas, 4) la politica, 5) las fuentes documentales. Campos asociados a las condiciones espaciales y } \\
\text { temporales, al género discursivo y al vocabulario conceptual. }\end{array}$ \\
\hline $\begin{array}{l}\text { PACHECO- } \\
\text { LISSANDRE- } \\
\text { LLO }\end{array}$ & $\begin{array}{l}\text {-Campos semánticos temáticos: 1) los trabajadores y el mundo sindical, 2) las organizaciones politicas, 3) las } \\
\text { fuentes documentales. Campos asociados a las condiciones espaciales y temporales, al género discursivo y al } \\
\text { uso de vocabulario conceptual. }\end{array}$ \\
\hline & $\begin{array}{l}\text {-Campos semánticos temáticos: 1) la violencia, la represión y las fuerzas represivas, 2) las fuentes documentales, } \\
\text { 3) la politica, 4) los estudiantes, 5) el mundo laboral. Campos asociados a las condiciones espaciales y } \\
\text { temporales, al género discursivo y al uso de vocabulario conceptual. }\end{array}$ \\
\hline
\end{tabular}

Fuente: Elaboración propia.

La identificación de las elecciones de categorización y calificación agrega elementos que permiten reconstruir las posiciones (políticas, ideológicas, afectivas o profesionales) en las que se inscriben las instancias de enunciación, a partir del empleo de ítems léxicos definidos. En la Tabla 4 nombramos los principales campos semánticos ${ }^{24}$ temáticos presentes en los artículos.

24 La noción de "campo semántico" ha sido objeto de múltiples definiciones. En este trabajo, optamos por considerar al campo semántico como campo conceptual, nocional o noemático. "Estos campos son totalidades, o sectores conceptuales, por ejemplo, la belleza, la justicia, el amor, etc., creadas con una metodología onomasiológica, que, teniendo un valor semántico unitario, abarcan todas las palabras que implican un determinado concepto" (Alcaraz 95). 
Asimismo, registramos la presencia, en todos los casos, de campos asociados a las condiciones espaciales y temporales, al género discursivo y/o al uso de vocabulario conceptual o disciplinar. Respecto de los campos temáticos, es significativa la presencia, en casi todos los casos, de conjuntos de ítems léxicos asociados a la represión, las fuerzas represivas y/o los servicios de inteligencia -con excepción del artículo de Julieta Pacheco y Guido Lissandrello-, y de otro grupo vinculado al uso de fuentes documentales, testimoniales y/o periodísticas, entre las que se encuentra la documentación del archivo de la DIPBA. En el caso de los artículos que utilizan la documentación de este acervo como objeto de estudio - pero también en aquellos que hacen uso de otras fuentes testimoniales o documentales como objetos de análisis-, es recurrente el uso del tiempo verbal presente y la ubicación de las fuentes en posición sintáctica variable como sujeto sintáctico, objeto o circunstancial de lugar-, lo que las coloca en el mismo plano de la enunciación, como objetos que son leídos, recuperados o apropiados de diversas formas en el marco de la situación de enunciación: "El testimonio de Ana María nos permite recuperar" (Barragán 232), "La lectura del conjunto de los Legajos nos permite observar" (Casola 55). Por su parte, el campo semántico relativo al género discursivo participa del despliegue de la escena, así como algunos de los ítems léxicos relacionados a las condiciones temporales y espaciales, aunque en este último caso se vinculan sobre todo a la enunciación histórica o relato como marcadores que permiten el encuadre de los distintos procesos y acontecimientos relatados.

Entre los campos semánticos reconstruidos, encontramos recurrencia de vocabulario especializado, que participa de la construcción del ethos o inscripción científico-académica de las instancias de enunciación. El estilo formal es predominante, con léxico especializado y locuciones nominales con valor categorial, verbos de estilo formal, adjetivos con valor conceptual y adverbios con valor modalizador y de estilo formal. Si bien hay presencia de discurso coloquial, no registramos casos en que no estuviese entrecomillado -“bien pagos" (Barragán 228), "cara a cara" (Pacheco 161), entre otras-. Estos elementos participan de la producción de efectos de objetividad, formalidad y cientificidad.

No obstante, en muchos casos la inscripción científico-académica se ve hibridada por elementos discursivos que reenvían a modalidades de inscripción política y afectiva. Específicamente, registramos marcadores del campo discursivo de los derechos humanos y de la ciudadanía, y otros que inscriben a las posiciones de enunciación en un campo antagónico o contrario al de las dictaduras, las fuerzas represivas o los servicios de inteligencia. Los elementos más recurrentes son marcas evaluativas de carácter axiológico y marcas apreciativas (Kerbrat- 
Orecchioni), que además participan, como veremos más abajo, de la articulación o inscripción de las instancias de enunciación con los relatos históricos: "El accionar represivo desplegado en el INTA incluyó detenciones y secuestros a trabajadores del organismo -dentro de los cuales al menos cinco permanecen desaparecidos-" (Gárgano 8), "Las consecuencias aún están vigentes" (Funes, "Ingenieros" 436).

Tabla 5-1: Transtextualidad y heterogeneidad mostrada ( $1^{\mathrm{a}}$ parte).

\begin{tabular}{|c|c|}
\hline \multirow{2}{*}{ Artículo } & \multirow{2}{*}{$\begin{array}{c}\text { Tabla V }\left(1^{\circ} \text { parte }\right) \\
\text { Transtextualidad y heterogen eidad mostrada }\end{array}$} \\
\hline & \\
\hline BARRAGAN4 & $\begin{array}{l}\text {-Intertex to: Referencias a fuentes teóricas y analiticas, a fuentes documentales y testimoniales. Referencias al } \\
\text { archivo de la DIPBA en notas al final. } \\
\text { - Modalidades de citación: Estilo directo predominante. Recurrencia del discurso indirecto, a veces vinculado a } \\
\text { citas tex tuales. Uso de comillas y otras marcas de distancia para introducir discurso coloquial, marcar distancia o } \\
\text { introducir categorias nativas. } \\
\text { - Modalidades de comentario y reformulación: Casos de comentarios sobre el discurso referido directo, con } \\
\text { carácter en ciertos casos evaluativo. } \\
\text {-Presentación de la documentación del archivo de la DIPBA: Los documentos son presentados como fuentes } \\
\text { documentales. Se recurre al uso de notas al final en fragmentos de texto sin comillas, con carácter informativo y } \\
\text { tono asertivo. }\end{array}$ \\
\hline CASOLA2 & $\begin{array}{l}\text {-Intertex to: Referencias a fuentes teóricas y analiticas en el cuerpo del tex to y al final, y a fuentes documentales, } \\
\text { sobre todo del archivo de la DIPBA, en notas al pie. } \\
\text { - Modalidades de citación: Estilo directo e indirecto, que a veces se articula con discurso directo. Uso de comillas } \\
\text { yotras marcas de distancia para referirse a categorias, marcar distancia o para introducir elementos de una doxa. } \\
\text { - Modalidades de comentario y reformulación: Se registran marcas de concordancia, de actitud neutra y } \\
\text { comentarios evaluativos en relación al discurso de la DIPBA, muchas veces con carácter desvalorizante. } \\
\text {-Presentación de la documentación del archivo de la DIPBA: Se divide entre una actitud neutra vinculada a lo } \\
\text { que los documentos informan, y una actitud polémica que tiende a problematizar explicitamente su contenido. }\end{array}$ \\
\hline D'ANTONIOI & $\begin{array}{l}\text {-Intertex to: Referencias a fuentes documentales, entre las que se sitúan documentos del archivo de la DIPBA, y } \\
\text { algunas referencias a fuentes analiticas, presentadas en notas al pie y al final. } \\
\text { - Modalidades de citación: Discurso referido indirecto, articulado en alg unos casos con citas tex tuales o discurso } \\
\text { directo. Uso de comillas para categorias, y como marcas de distancia. } \\
\text { - Modalidades de comentario y reformulación: Modalidades que introducen discurso ajeno con uso de evaluación } \\
\text { o calificación marcada. En algunos casos, la evaluación posee carácter axiológico desvalorizante. } \\
\text {-Presentación de la documentación del archivo de la DIPBA: Algunos documentos del archivo son utilizados } \\
\text { como fuentes de ejemplos que sostienen el desarrollo del análisis, es decir que están vinculados al análisis de las } \\
\text { representaciones y caracterizaciones imperantes en el seno del "régimen militar". También son utilizados } \\
\text { documentos o material secuestrado o anexo, en este caso las referencias se hacen en notas al pie. }\end{array}$ \\
\hline FUNE S3 & $\begin{array}{l}\text {-Intertexto: Referencias a fuentes teóricas y analiticas sobre todo en notas al pie, a fuentes documentales; } \\
\text { predominan referencias al discurso de la DIPBA, que se citan en notas al pie. } \\
\text {-Modalidades de citación: Discurso referido directo e indirecto, en este caso articulado a veces con citas } \\
\text { textuales. Uso de comillas y otras marcas de distancia para introducir categorias, marcar distancia o discurso } \\
\text { coloquial. } \\
\text { - Modalidades de comentario y reformulación: Presencia de algunas marcas de concordancia, de comentarios que } \\
\text { evalúan el discurso ajeno (en el caso del discurso de la DIPBA, con actitud neutra o desvalorizante). } \\
\text {-Presentación de la documentación del archivo de la DIPBA: Se divide entre una actitud neutra vinculada a lo } \\
\text { que informan los documentos, y una actitud polémica que tiende a desacreditar las posiciones de enunciación de } \\
\text { los informes. }\end{array}$ \\
\hline GARGANO2 & $\begin{array}{l}\text {-Intertexto: Referencias a fuentes teóricas y analíticas, y a fuentes documentales y entrevistas. } \\
\text {-Modalidades de citación: Discurso referido indirecto, en articulación con citas textuales, pero también se } \\
\text { registran casos de discurso directo, en articulación o no con estilo indirecto. Registramos el uso de comillas y } \\
\text { otras marcas de distancia para el uso de categorias, introducción de elementos dóxicos, o para marcar distancia } \\
\text { ideológica. } \\
\text { - Modalidades de comentario y reformulación: Marcas de concordancia, de actitud neutra, de distancia con uso de } \\
\text { condicional y de actitud polémica. } \\
\text {-Presentación de la documentación del archivo de la DIPBA: Salvo la mención de "los cables enviados" por } \\
\text { personal de la DIPBA y la indicación de los materiales en "Otras fuentes", no hay presentación y calificación de } \\
\text { la documentación. }\end{array}$ \\
\hline
\end{tabular}

Fuente: Elaboración propia. 
Tabla 5-2: Transtextualidad y heterogeneidad mostrada ( $2^{\mathrm{a}}$ parte).

\begin{tabular}{|c|c|}
\hline \multirow{2}{*}{ Artículo } & Tabla V ( $2^{\circ}$ parte $)$ \\
\hline & Transtextualidad y heterogen eidad mostrada \\
\hline KAHAN6 & $\begin{array}{l}\text {-Intertexto: Referencias a fuentes teóricas y analiticas, y a fuentes periodisticas y documentales, entre las que se } \\
\text { sitúan legajos del archivo de la DIPBA. } \\
\text { - Modalidades de citación: Discurso referido directo e indirecto, a veces en articulación con citas tex tuales. Uso } \\
\text { de comillas como marcas de categorias, de distancia o discurso coloquial. } \\
\text { - Modalidades de comentario y reformulación: Marcas de concordancia, de actitud neutral y de actitud polémica, } \\
\text { casi siempre en relación a otros estudios del campo disciplinar. } \\
\text {-Presentación de la documentación del archivo de la DIPBA: la documentación es referida en notas al final, y la } \\
\text { presentación man fene una actitud neutral. La presentación refiere a la documentación de la DIPBA como fuente } \\
\text { documental. Sin embargo, hay referencias recurrentes al uso del archivo como objeto de estudio. }\end{array}$ \\
\hline $\begin{array}{c}\text { MARE NGO- } \\
\text { CASTRO- } \\
\text { NUOVO }\end{array}$ & $\begin{array}{l}\text {-Intertexto: Referencias a fuentes teóricas y analiticas, y a fuentes documentales, entre las que se hayan } \\
\text { documentos del archivo de la DIPBA, a entrevistas y testimonios, leyes y decretos. } \\
\text { - Modalidades de citación: Discurso referido directo e indirecto, que a veces se articula con citas tex tuales. Las } \\
\text { comillas y otras marcas de distancia como las bastardillas se utilizan para categorias, o para marcar distancia } \\
\text { ideológica. } \\
\text { - Modalidades de comentario y reformulación: Hay marcas de concordancia y comentarios que califican o } \\
\text { evalúan el discurso ajeno, sobre todo en el caso de las entrevistas y testimonios. } \\
\text {-Presentación de la documentación del archivo de la DIPBA: Las referencias a los documentos de la DIPBA } \\
\text { mantienen una actitud neutra, descriptiva, en algunos casos es utilizada como fuente documental. }\end{array}$ \\
\hline PACHE CO4 & $\begin{array}{l}\text {-Intertex to: Referencias a fuentes teóricas y analiticas, y a fuentes documentales, entre las que se situan legajos } \\
\text { del archivo de la DIPBA. } \\
\text {-Modalidades de citación: Discurso referido directo e indirecto, en este último caso muchas veces en articulación } \\
\text { con citas tex tuales. Uso de comillas para categorias, como marcas de distancia o de discurso coloquial. } \\
\text {-Modalidades de comentario y reformulación: Marcas de concordancia y de actitud neutral. En algunos casos, el } \\
\text { discurso referido hace uso de verbos de reformulación con una modalidad evaluativa marcada. } \\
\text {-Presentación de la documentación del archivo de la DIPBA: las referencias son a material secue strado por la } \\
\text { DIPBA producido por las organizaciones analizadas, tales como volantes. }\end{array}$ \\
\hline $\begin{array}{l}\text { PACHE CO- } \\
\text { LISSANDRE- } \\
\text { LLO }\end{array}$ & $\begin{array}{l}\text {-Intertexto: Referencias a fuentes teóricas y analiticas, y a fuentes documentales, entre las que se sitúan } \\
\text { documentos del archivo de la DIPBA. } \\
\text { - Modalidades de citación: Discurso referido directo e indirecto, muchas veces en articulación con citas textuales. } \\
\text { Se registra uso de comillas sobre todo para categorias nativas yó analiticas ajenas. } \\
\text { - Modalidades de comentario y reformulación: Sobre todo, marcas de concordancia. En algunos casos, el } \\
\text { discurso referido indirecto hace uso de verbos de reformulación con una modalidad evaluativa marcada. } \\
\text {-Presentación de la documentación del archivo de la DIPBA: la documentación del archivo sólo es referida en } \\
\text { una nota al final, como contenedor de una publicación de la Juventud Trabajadora Peronista (material } \\
\text { secuestrado). }\end{array}$ \\
\hline ZAPATA4 & $\begin{array}{l}\text {-Intertex to: Referencias a fuentes teóricas y analiticas, y a fuentes documentales y testimoniales, en el cuerpo del } \\
\text { tex to y en notas al final. Hay referencias a documentación del archivo de la DIPBA, y reproducción de extractos } \\
\text { de informes. } \\
\text {-Modalidades de citación: Discurso directo e indirecto, que se asocia en algunos casos a citas textuales. Hay uso } \\
\text { de comillas y otras marcas de distancia en relación a categorias, para marcar distancia ideológica, o para } \\
\text { introducir elementos de la doxa. } \\
\text { - Modalidades de comentario y reformulación: Marcas de concordancia yo actitud neutra, que en algunos casos } \\
\text { funcionan como comentarios para calificar el discurso ajeno. También hay presencia de marcas que comentan en } \\
\text { términos negativos el discurso de la DIPBA. } \\
\text {-Presentación de la documentación del archivo de la DIPBA: Se registra una actitud polémica en la presentación } \\
\text { del discurso de la DIPBA, reconstruyéndose la "lógica" de este servicio. }\end{array}$ \\
\hline
\end{tabular}

\section{Fuente: Elaboración propia.}


La identificación de las formas de transtextualidad ${ }^{25}$ y heterogeneidad mostrada ${ }^{26}$ presentes en los artículos puede ser observada en la Tabla 5. Dicha identificación exhibe la recurrencia de referencias intertextuales a fuentes bibliográficas, utilizadas tanto como fuentes analíticas o documentales de datos comprobados. También es recurrente la presentación de un breve estado del arte y de otras investigaciones del campo disciplinar, especificando en ciertos casos los vacíos problemáticos y marcos generales en los que se inscriben o sitúan los artículos (como "investigaciones en curso"). En este contexto, se han registrado pocos casos de discusión teórica o disenso en el estado del arte.

También es regular la presencia de referencias a fuentes documentales, entre las que se sitúa la documentación del archivo de la DIPBA, pero se registra, asimismo, la utilización de otros acervos archivísticos. Los tipos documentales más recurrentes son documentos producidos por personal de dicha agencia, predominantemente informes pero también memorandos policiales, entre otros. También hay referencias a volantes, gacetillas, revistas y otros tipos documentales producidos por los sujetos que fueron objeto de vigilancia de la DIPBA, material secuestrado por sus agentes y recopilado en los legajos. Por otra parte, los artículos hacen uso de otras fuentes, de carácter testimonial o periodístico, vinculadas a otros fondos documentales o de elaboración propia, como las entrevistas. ${ }^{27}$ Esta hibridación de fuentes testimoniales y documentales es variable, observándose dominancias específicas en ciertos subconjuntos de artículos. En las producciones de Ivonne Barragán, Zapata, Gárgano, y María Eugenia Marengo y Sabrina Castronuovo se registra el uso de fuentes documentales y testimoniales, mientras que el resto de las publicaciones sólo utiliza fuentes documentales.

En general, la aparición de estas referencias como despliegue o construcción del intertexto de los artículos funciona a modo de "puesta en escena" del contexto,

La transtextualidad remite a las distintas formas de trascendencia textual del texto, es decir, a "todo lo que pone al texto en relación, manifiesta o secreta, con otros textos" (Genette 9-10), e incluye al menos cinco tipos de relaciones transtextuales: intertextualidad, paratextualidad, metatextualidad, hipertextualidad y arquitextualidad.

La heterogeneidad mostrada "corresponde a la presencia localizable de otro discurso en el fluir del texto. Se distingue entre las formas no marcadas de esta heterogeneidad y sus formas marcadas (o explícitas). El coenunciador identifica las formas no marcadas (discurso indirecto libre, alusiones, ironía, pastiche...) combinando en proporciones variables la localización de índices textuales o paratextuales diversos y la activación de su cultura personal. Las formas marcadas, en cambio, se señalan de manera unívoca: puede tratarse de discurso directo o indirecto, de comillas, pero también de glosas que indican una no coincidencia del enunciador con lo que dice (modalización autonímica)" (Charaudeau y Maingueneau 298).

27 Es recurrente la indicación pormenorizada de las referencias a estos acervos en notas al pie o en el cuerpo de los textos. 
del referente y, por tanto, de las condiciones discursivas de producción ${ }^{28}$ de las publicaciones. Como plantea Paolo Fabbri, la operación científica por excelencia "no consiste en ocultar las condiciones de producción sino en colocarlas en el lugar de la representación que los autores tratan de mostrar" (Fabbri, Tácticas 279). Ocurre como si los artículos científicos intentaran convencer "presentando capas de textos que se corresponden y que sirven de referentes las unas a las otras" (Fabbri, Tácticas 277). Además, la presentación del intertexto participa en la construcción del ethos científico-académico, por su producción de un efecto de "competencia" y "conocimiento" de la bibliografía y el material documental. La construcción del referente y del contexto se despliegan mediante una superposición de textos, cuya presentación es valorada de distintas maneras mediante comentarios, modalidades y formas de citación.

Entre los modos de citación, registramos la presencia de distintos estilos. Es recurrente el uso de discurso referido directo e indirecto, con dominancia de uno u otro según los casos, pero también es usual la articulación de estilo indirecto con citas textuales y la hibridación entre discurso directo e indirecto. En muchos casos estos recursos son utilizados para reponer la perspectiva de los sujetos o grupos objetos de estudio. En los artículos de Natalia Casola, Patricia Funes y Ana Belén Zapata, por ejemplo, se registra un análisis pormenorizado de las fuentes documentales del archivo de la DIPBA articulado a una reposición de su "lógica" (Zapata 125) o punto de vista. Junto con el artículo de Débora D'Antonio, este subconjunto de publicaciones recurre a distintos recursos que configuran una actitud de lectura y presentación polémica del discurso de los servicios de inteligencia, el gobierno militar o las fuerzas represivas.

En todos los artículos analizados registramos uso de comillas y otras marcas de heterogeneidad mostrada, vinculadas a la presentación de nociones o categorías (propias o ajenas), pero también para marcar distancia político-ideológica -"la autodenominada 'Revolución Libertadora"' (Gárgano 4)- o discurso coloquial. Asimismo, es recurrente la presencia de marcas de concordancia - "como ya lo ha señalado", "en consonancia con otros trabajos", etcétera-, normalmente en referencia a otras publicaciones del campo disciplinar, marcas de actitud neutra, y comentarios y reformulaciones del discurso ajeno con carácter evaluativo valorizante o desvalorizante -en el caso del discurso de las fuerzas represivas-: "Las afirmaciones carecían de sustento y adjudicaba a los grupos chilenos exiliados una logística y una capacidad de operación militar equivalente a la de una guerrilla

28 Esta noción hace referencia a "todo aquello que el analista considerará, por hipótesis, como elementos que desempeñan un papel determinante para explicar las propiedades de los discursos analizados", y "contienen siempre otros discursos" (Verón 41). 
nativa con experiencia y cierto tiempo de organización" (Casola 58), "Todo esto tenía más importancia para los servicios que ahondar en los posibles implicados en el homicidio" (Zapata 123). Estos marcadores inciden en la construcción argumentativa del consenso y el disenso (polémica) en el campo disciplinar, pero también en la evaluación de las fuentes documentales y testimoniales, como sucede con la documentación del archivo de la DIPBA.

Según pudimos identificar, la presentación de los documentos del archivo de la DIPBA adquiere por lo menos tres modalidades. En primer lugar, existe un uso de su documentación como fuente informativa, es decir, los documentos son utilizados para la extracción de datos que son presentados en los artículos haciendo referencia a dicho acervo. En segundo lugar, registramos formas de presentación de su contenido que hacen uso de una actitud "neutra", esto es, se cita el contenido de los informes y otros documentos sin valoración ni presencia de marcas axiológicas o apreciativas. En tercer lugar, hallamos un subconjunto de artículos que presentan una modalidad polémica de presentación de la discursividad de la DIPBA en tanto servicio de inteligencia policial. En este último caso, la reconstrucción del punto de vista de la agencia es variable, sin embargo hay recurrencia de marcas evaluativas de carácter axiológico desvalorizantes, técnicas de refutación -"La anacrónica frase 'contraespionaje' y 'correspondencia subversiva', desnuda esa intencionalidad que señaláramos antes" (Funes, "Ingenieros" 422), "Entre los principales argumentos se apelaba a tratados que se remontaban a los tiempos coloniales, inclusive a la propia fundación de Buenos Aires en el siglo XVI, cuando ni siquiera los más avezados exploradores tenían certeza sobre límites y fronteras" (Casola 60-61)-, y otros recursos como ironía - "Como vemos, en la hermenéutica de los asesores literarios el rango de la apología o la detracción es muy amplio" (Funes, "Ingenieros" 432), "Muy antiguos orígenes para muy contemporáneas necesidades de legitimidad" (Funes, "Ingenieros" 422)-, marcas apreciativas -"silenciaron esos sonidos para toda una generación, sin embargo no lograron arrancarlos definitivamente de los corazones de la cultura popular" (Funes, "Ingenieros" 430)- o la representación de la DIPBA y sus agentes con estados psicológicos que van de la "preocupación" a la "sugestión" o la "paranoia", lo que sirve para desacreditar su discurso y evaluar su valor informativo:

Dicho por el Director de uno de los principales servicios de inteligencia del país habría que creerle, sin embargo, es posible que el clima de riña propio de la coyuntura haya 'sugestionado' a quienes imaginaban encarnar la defensa de la patria contra un enemigo que había que materializar poniendo nombre y apellido. (Casola 62) 
En todo caso, podemos indicar que el ingreso de las fuentes bibliográficas, documentales y testimoniales en la situación de enunciación las ubica como objetos circulantes que son utilizados y valorados de diferentes formas por el enunciador, incidiendo en la multiplicación del referente (Fabbri, Tácticas 275), pero también en la producción de efectos de prueba o evidencia. Se trata de un proceso de objetivación discursiva de las fuentes. Normalmente, el discurso ajeno se encuentra intercalado por marcadores, de carácter metadiscursivo o metatextual, que reenvían al marco enunciativo, utilizados para estructurar el desarrollo del artículo y producir efectos de lectura, análisis, síntesis o prueba. Por ejemplo: "El testimonio de Ana María nos permite recuperar" (Barragán 232), "A pesar de estos cambios simbólicos para la época, en los archivos de la Dirección de Inteligencia se evidencia" (Marengo y Castronuovo 123).

Tabla 6-1: Enunciación y relato $\left(1^{\mathrm{a}}\right.$ parte $)$.

\begin{tabular}{|c|c|}
\hline \multirow{2}{*}{ Artículo } & \multirow{2}{*}{$\begin{array}{c}\text { Tabla VI }\left(1^{0} \text { parte }\right) \\
\text { Enunciación y relato }\end{array}$} \\
\hline & \\
\hline BARRAGAN4 & $\begin{array}{l}\text { Predomina la enunciación histórica (excepto en introducción y conclusiones), intercalada con marcas que refieren } \\
\text { al marco enunciativo. Casos de hibridación de tiempos verbales (presente histórico + pretérito), marcas de } \\
\text { inscripción afectiva del enunciador en el relato, y marcas de inscripción politica propias del discurso de los } \\
\text { derechos humanos, que en algunos casos articula la situación de enunciación del articulo con el relato histórico. }\end{array}$ \\
\hline CASOLA2 & $\begin{array}{l}\text { Predomina la enunciación histórica, intercalada con referencias al marco enunciativo (sobre todo en introducción } \\
\text { y conclusiones). La inscripción politica y afectiva de las instancias de enunciación en el relato se desarrolla a } \\
\text { partir de marcas de carácter axiológico yio apreciativo, en muchos casos asociadas al discurso de los Derechos } \\
\text { Humanos, pero también hay presencia de topos que dirigen a la producción de efectos emocionales o pasionales, } \\
\text { y recursos dirigidos a la desacreditación del discurso de la DIPBA. La DIPBA y sus agentes son representados } \\
\text { con estados psicológicos que van de la "preocupación" a la "paranoia". También hay asignación explicita de la } \\
\text { responsabilidad, y técnicas de refutación varias. }\end{array}$ \\
\hline D'ANTONIO1 & $\begin{array}{l}\text { Predomina la enunciación histórica, intercalada con referencias metadiscursivas. Hay recurrencia de marcas de } \\
\text { inscripción politica y afectiva del enunciador en los relatos, la mayoria relativas al discurso de los Derechos } \\
\text { Humanos, construcciones orientadas a la producción de efectos emocionales o pasionales como la indignación, y } \\
\text { técnicas de refutación como la desmitificación. }\end{array}$ \\
\hline FUNE S3 & $\begin{array}{l}\text { La enunciación histórica predomina, en articulación con referencias al marco enunciativo. Se registran marcas } \\
\text { evaluativas de carácter axiológico desvalorizante, marcas apreciativas y construcciones dirigidas a provocar } \\
\text { efectos emocionales o pasionales, que inciden en la inscripción politica y afectiva de las instancias de } \\
\text { enunciación. Hay una articulación entre pasado y presente, entre relato histórico y enunciación, a partir de una } \\
\text { inscripción afectiva: "Las consecuencias aún están vigentes". También son utilizados diversos recursos } \\
\text { argumentativos y técnicas de refutación del discurso de la DIPBA, como la ironia, la desmitificación, entre otras. }\end{array}$ \\
\hline GARGANO2 & $\begin{array}{l}\text { La enunciación histórica es predominante (salvo en introducción y conclusiones, donde hay recurrencia de } \\
\text { referencias al marco enunciativo, como las autorreferencias y marcadores metatextuales). En el resto del articulo } \\
\text { hay presencia de marcadores metadiscursivos y metatextuales que estructuran el articulo, asi como } \\
\text { construcciones vinculadas a la producción de "pruebas". No se registran marcas de inscripción afectiva de las } \\
\text { instancias de enunciación, aunque las marcas de distancia y otros elementos como elecciones de categorización y } \\
\text { calificación permiten interpretar una inscripción politica. }\end{array}$ \\
\hline
\end{tabular}

Fuente: Elaboración propia. 
Tabla 6-2: Enunciación y relato ( $2^{\mathrm{a}}$ parte).

\begin{tabular}{|c|c|}
\hline \multirow{2}{*}{ Artículo } & Tabla VI ( $2^{\circ}$ parte $)$ \\
\hline & \begin{tabular}{|l|} 
Enunciación y relato \\
\end{tabular} \\
\hline KAHAN6 & $\begin{array}{l}\text { El articulo comienza con un relato sobre la presentación del archivo de la DIPBA en la prensa argentina, con } \\
\text { recurrencia de tercera persona y pretérito. Posteriormente, el articulo se centra en el abordaje de las perspectivas } \\
\text { de análisis y el desarrollo de la investigación, con recurrencia de tiempo presente y marcadores metadiscursivos } \\
\text { y metatextuales. Se registra una mención a la "experiencia del terrorismo de Estado", con uso de tiempo } \\
\text { comentativo (pretérito perfecto compuesto), como modo de articular en términos espaciales y temporales la } \\
\text { enunciación con el relato histórico; en este caso, la referencia al "carácter traumático" de la experiencia } \\
\text { constituye una modalidad de inscripción apreciativa o afectiva. }\end{array}$ \\
\hline $\begin{array}{l}\text { MARE NGO- } \\
\text { CASTRO- } \\
\text { NUOVO }\end{array}$ & $\begin{array}{l}\text { La enunciación histórica se utiliza en el relato que desarrolla la historia de la DIPBA y su archivo, y en los } \\
\text { relatos reconstruidos a partir de las entrevistas, intercaladas por referencias al marco enunciativo. Hay marcas } \\
\text { axiológicas y apreciativas, y construcciones dirigidas a producir efectos emocionales. En las conclusiones se } \\
\text { ex plicita una inscripción politica del enunciador como ciudadano. }\end{array}$ \\
\hline PACHE CO4 & $\begin{array}{l}\text { E1 articulo intercala referencias metadiscursivas y a los componentes del marco enunciativo, y enunciación } \\
\text { histórica. No registramos presencia de marcas de inscripción afectiva de las instancias de enunciación en los } \\
\text { relatos, aunque si puede interpretarse una inscripción politico-ideológica "de izquierda" por ciertas elecciones de } \\
\text { categorización y calificación. }\end{array}$ \\
\hline $\begin{array}{l}\text { PACHE CO- } \\
\text { LISSANDRE- } \\
\text { LLO }\end{array}$ & $\begin{array}{l}\text { La enunciación histórica es predominante excepto en introducción, donde la presencia de marcas que reenvian a } \\
\text { los componentes del marco enunciativo son más recurrentes. Sin embargo, los relatos están intercalados con } \\
\text { marcadores metadiscursivos que reenvian a la posición del enunciador, y que estructuran el articulo y la } \\
\text { construcción de las "pruebas". No registramos presencia de marcas de inscripción politica o afectiva de las } \\
\text { instancias de enunciación en los relatos. }\end{array}$ \\
\hline ZAPATA4 & $\begin{array}{l}\text { La enunciación histórica predomina en el articulo, salvo en introducción y conclusiones. Sin embargo, hay } \\
\text { recurrencia de referencias al marco enunciativo. Si bien registramos pocas marcas de inscripción afectiva de las } \\
\text { instancias de enunciación con los relatos a partir de marcas apreciativas, si observamos un uso asiduo de } \\
\text { recursos que permiten posicionar politicamente al enunciador: comentarios sobre el discurso ajeno con carácter } \\
\text { desvalorizante, ironia, elecciones de categorización y calificación, etcétera. }\end{array}$ \\
\hline
\end{tabular}

Fuente: Elaboración propia.

Por último, se han identificado y analizado las relaciones entre enunciación y relato ${ }^{29}$ en los artículos (Tabla 6). En todos registramos la presencia de enunciación histórica, ${ }^{30}$ intercalada -en mayor o menor medidacon referencias al marco enunciativo. En este sentido, estos comentarios, vinculados a la situación de enunciación, participan de la producción de "hechos" y "acontecimientos". Este proceso de construcción fáctica exhibe la presencia de estrategias de expresión de evidencialidad, como las referencias a fuentes documentales y testimoniales y la mención de los procesos y tareas realizados por los investigadores -lectura de documentos, realización de entrevistas, entre

29 En el enunciado es posible distinguir una capa que corresponde al nivel de lo expresado, la información transmitida o la historia contada (relato). En este caso, el sujeto del enunciado es "el yo de un hacer diverso en cada caso" (Filinich 19). La relación entre enunciación y relato se construye mediante determinadas operaciones de encuadre, a partir de los cuales las instancias de enunciación se sitúan en relación con lo expresado desde un determinado punto de vista.

30 "La enunciación «histórica» que corresponde esencialmente a la lengua escrita, narra los acontecimientos pasados sin ninguna intervención del hablante. La «historia» no puede utilizar otra persona que la tercera; excluyendo todo lo que es propio del aparato formal del «discurso»" (Maingueneau 118). 
otras-. Por ejemplo: "La reconstrucción de la trayectoria de organización obrera en esta fábrica visibilizó" (Barragán 234), "Esta primera aproximación al rol de las mujeres en el astillero nos permitió reponer" (Barragán 233), "podemos leer desde la prensa" (Zapata 115). También hay presencia de modalidades epistémicas que permiten calibrar el grado de certeza de los enunciados: "Interpretamos entonces", "Creemos que", etcétera.

No obstante, también pudimos identificar efectos de inscripción política y afectiva de las instancias de enunciación que se despliegan a nivel de la articulación entre enunciación y relato histórico. Mediante distintos recursos, como el uso de técnicas de refutación, la presentación polémica del discurso de la DIPBA, la presencia de marcas evaluativas de carácter axiológico y de marcas apreciativas, la hibridación de tiempos verbales ligados a la enunciación y al relato, y construcciones dirigidas a la producción de efectos emocionales o pasionales, es posible señalar la recurrencia de una inscripción político-ideológica $-\mathrm{y}$, en ciertos casos, también afectiva- de las instancias de enunciación de los artículos, posicionada en torno a los relatos históricos presentados: "la herencia de esa destrucción aún nos atraviesa" (Funes, "Ingenieros" 436), "en su relato da cuenta del terror que esta situación implicaba" (Barragán 238), "fue secuestrada el 16 de marzo de 1977 y continúa desaparecida” (Barragán 228).

\section{CONCLUSIONES}

En este artículo nos hemos propuesto explorar aspectos del reconocimiento contemporáneo del archivo de la DIPBA, particularmente sus modalidades de uso y lectura en el ámbito científico-académico. Se trató de una primera aproximación que, ubicada desde una perspectiva intepretativa, utilizó métodos cuantitativos y cualitativos con el propósito de exhibir distintos modos de trabajo con dicho acervo. Por su carácter inicial y acotado, no es nuestra intención adelantar conclusiones definitivas, sino utilizar el análisis realizado hasta aquí en función de la apertura de nuevos interrogantes de investigación y para el planteo de hipótesis.

El análisis estadístico de los artículos de investigación científica muestra el crecimiento exponencial en los usos y menciones de este fondo archivístico en la literatura académica de los últimos años, así como la multiplicidad de abordajes disciplinares de la que ha sido y es objeto. A su vez, este abordaje ha permitido exhibir la jerarquía de intereses temáticos, la cual se encuentra definida por las condiciones de las distintas áreas disciplinares que han hecho uso del archivo, $\mathrm{y}$ ha permitido identificar dominancias en torno a su utilización como fuente documental y a los períodos abordados a partir de su documentación. 
Desde la consideración de este "archivo de la represión" o "de control social" como territorio de memoria, es posible conceptuar las producciones del ámbito científico-académico en las que se aborda, utiliza o menciona el archivo de la DIPBA como modalidades particulares de apropiación del archivo, como prácticas de marcación que inciden en su construcción como lugar de memoria y de historia. Sin embargo, la consideración de las publicaciones académicas como prácticas de apropiación y uso del archivo también autoriza a pensar en los modos de "expansión" del mismo como territorio. Específicamente, el análisis topográfico permite reflexionar sobre las formas contemporáneas de circulación de su documentación, que cobra un carácter inverso al modo característico del período de funcionamiento de la DIPBA (1956-1998), en el que las producciones de las delegaciones de inteligencia situadas en diferentes distritos de la Provincia de Buenos Aires eran reunidas en el archivo ubicado en la sede central, en la ciudad de La Plata. Actualmente, la modalidad de circulación de los documentos del archivo puede ser caracterizada como "centrífuga", teniendo en cuenta su fragmentación en una multiplicidad de apropiaciones de nuevos usuarios que realizan consultas y pedidos de documentación.

El análisis discursivo de un conjunto de artículos inscriptos en los estudios de historia reciente nos ha permitido, a su vez, indagar y caracterizar la presentación discursiva de las relaciones entre investigadores y documentación, y su participación en el dispositivo de producción de representaciones consensuadas sobre el pasado reciente. A partir de la identificación de cuatro grupos de categorías analíticas, nos fue posible reconstruir elementos del dispositivo de enunciación desplegado por los artículos de investigación científica seleccionados. Dicho dispositivo puede ser conceptuado como un mecanismo genérico-enunciativo productor de efectos de cientificidad, objetividad, evidencialidad y construcción fáctica. En este contexto, el trabajo con las fuentes documentales -entre las que se ubica la documentación del archivo de la DIPBA- ingresa como componente de la situación de enunciación construida en los artículos, en un proceso de objetivación discursiva de las fuentes.

Sin embargo, en un subconjunto de artículos se destaca una modalidad particular de presentación y calificación de la documentación del archivo que hemos caracterizado como "polémica", que problematiza el carácter de fuente documental de dicha documentación. Esta modalidad aparece como una particularidad de los estudios que analizan discursos o documentación producida por las fuerzas represivas, y se apoya en una discursividad definida, contrastante con el resto de los artículos: marcas evaluativas desvalorizantes, técnicas de refutación del discurso de la DIPBA o del gobierno dictatorial, uso de la ironía, marcas apreciativas, entre otros recursos. Si bien no se trata de una 
muestra representativa, podría reflejar la tendencia, por parte de un sector de las producciones que investigan a la DIPBA o a las fuerzas represivas mediante la exégesis de su propia discursividad, a la producción de comentarios de carácter axiológico en torno a esta documentación, a la problematización de su valor documental para la investigación histórica o al antagonismo frente a las posiciones de enunciación de sus agentes productores. ${ }^{31}$

Por último, hemos indicado la recurrencia en la construcción de un ethos científico-académico hibridado por elementos que marcan una oposición político-ideológica al accionar de las dictaduras militares, las fuerzas represivas o los servicios de inteligencia, según el caso, y que en ciertas publicaciones permite posicionar a sus instancias de enunciación en el campo discursivo de los Derechos Humanos o de la ciudadanía. No obstante, es posible registrar gran variabilidad en los marcadores discursivos y recursos utilizados, con efectos que inciden en la producción de diversas modalidades de inscripción: mayor o menor compromiso político, presencia o ausencia de inscripción afectiva, grados diversos en la producción de efectos de impersonalidad y objetividad a partir de los estilos y formas utilizadas, entre otros. Por su recurrencia, es posible que este efecto de "ethos híbrido" se fundamente en la constitución disciplinar del ámbito de estudios de historia reciente, siendo utilizado como "prueba" técnica dirigida a la producción de efectos persuasivos. En este sentido, se comprende la aparición de ciertas figuras enunciativas: el intelectual políticamente comprometido, el académico ubicado en los valores de la democracia y la ciudadanía, entre otras posibles. Esto sería coincidente con las apreciaciones de varios especialistas acerca de la relación entre las dimensiones ético-política y científico-académica como marca de origen del campo disciplinar.

En próximas investigaciones seguiremos examinando las modalidades de lectura y uso del archivo de la DIPBA en el ámbito de la historia reciente, lo que permitirá contrastar y comprobar la adecuación de la interpretación realizada en este trabajo, y proponer hipótesis alternativas.

31 Esto podría resultar coincidente con recientes señalamientos de Patricia Flier y Emmanuel Kahan sobre los efectos de la complejización y ampliación de la agenda de investigaciones académicas en el ámbito de la historia reciente, referentes a la producción de "una mayor sofisticación en el análisis de las fuentes" -en términos de su contrastación y crítica- así como "en la complejidad de las metodologías utilizadas y de los marcos teóricos, de la argumentación de los autores, de sus interpretaciones y conclusiones" (Flier y Kahan 159). 


\section{REFERENCIAS BIBLIOGRÁFICAS}

Acha, Omar. "Encrucijadas y obstinaciones en la distinción de historia y memoria: en torno a las prácticas memoriográficas en la Argentina". Jornadas Internacionales "Historia, memoria y patrimonio", Archivo General de la Nación / CEIRCAB - TAREA - Universidad Nacional de San Martín, 2010. https://doi.org/10.35537/10915/61051

Águila, Gabriela. "La Historia Reciente en la Argentina: un balance". Historiografías, no. 3, 2012, pp. 62-76.

---. "Policías, represión y «lucha antisubversiva»: exploraciones sobre el rol de las policías en el accionar represivo de los años 70 en Argentina". Folia Histórica del Nordeste, no. 32, 2018, pp. 121-146. https://doi. org/10.30972/fhn.0323500

Águila, Gabriela, Lucas Almada, María Alicia Divinsenzo, y Marianela Scocco. Territorio Ocupado. La historia del Comando del II Cuerpo de Ejército en Rosario (1960-1990). Editorial de la Municipalidad de Rosario, 2017.

Aguirre, Carlos, y Javier Villa-Flores. "Los archivos y la construcción de la verdad histórica en América Latina". Anuario de Historia Latinoamericana, vol. 46, no. 1, 2009, pp. 5-17. https://doi.org/10.7767/jbla.2009.46.1.5

Alcaraz Varó, Enrique, y María Antonia Martínez Linares. Diccionario de lingüística moderna. Ariel, 1997.

Aretxaga, Begoña. "Maddening states". Annual Review of Anthropology, vol. 32, 2003, pp. 393-410. https://doi.org/10.1146/annurev. anthro.32.061002.093341

Arnoux, Elvira. "El análisis del discurso como campo interdisciplinario". Análisis del Discurso. Modos de abordar materiales de archivo. Santiago Arcos, 2006, pp. 13-29.

Barragán, Ivonne. "Mujeres trabajadoras y delegadas sindicales en un astillero de la Armada Argentina. Astillero Río Santiago (1973-1978)". Nomadías, no. 20, 2015, pp. 227-248.

Besse, Juan. "Memoria urbana y lugares patrimoniales. Elementos teóricos para el abordaje de las marcas territoriales asociadas a acontecimientos políticos". Taller Internacional "Desplazamientos, contactos, lugares. La experiencia de la movilidad y la construcción de '-otras geografias-'”. Instituto de Geografía - UBA, 2005, pp. 1-27. https://doi.org/10.14350/ rig.30091

Briceño Velazco, Yosely. "Las marcas lingüísticas de obligación en artículos de investigación en tres disciplinas". Filología y Lingüistica, vol. 38, no. 2, 2012, pp. 77-95. https://doi.org/10.15517/rfl.v38i2.13086 
Casola, Natalia Laura. "Los indeseables. El exilio chileno en la mirada de la DIPBA (1973-1983)". Clepsidra. Revista Interdisciplinaria de Estudios sobre Memoria, vol. 4, no. 7, 2017, pp. 50-67.

Caswell, Michelle. "Khmer Rouge archives: accountability, truth, and memory in Cambodia". Archival Science, vol. 10, no. 1, 2010, pp. 25-44. https:// doi.org/10.1007/s10502-010-9114-1

Charaudeau, Patrick, y Dominique Maingueneau. Diccionario de análisis del discurso. Amorrortu, 2005. https://doi.org/10.4067/s007117132006000100020

D’Antonio, Débora Carina. "Derechos humanos y estrategias de la oposición bajo la dictadura militar argentina". Tensões Mundiais, vol. 6, no. 11, 2010, pp. 153-178.

---. "Vigilancia, control social y agencia política del activismo por los derechos humanos ante la llegada de la Comisión Interamericana de Derechos Humanos (Argentina, 1979)". Izquierdas, no. 32, 2017, pp. 184-202. https://doi.org/10.4067/s0718-50492017000100184

Da Silva Catela, Ludmila. "El mundo de los archivos". Los archivos de la represión: documentos, memoria y verdad, compiladoras Ludmila da Silva Catela y Elizabeth Jelin, Siglo XXI, 2002, pp. 195-221.

---. "Prólogo. La consagración de la memoria". La consagración de la memoria. Una etnografia acerca de la institucionalización del recuerdo sobre los crímenes del terrorismo de Estado en la Argentina. Ana Guglielmucci, Antropofagia, 2013,pp. 9-12. https://doi.org/10.7440/antipoda20.2014.08

---. "Territorios de memoria política. Los archivos de la represión en Brasil". Los archivos de la represión: documentos, memoria y verdad, compiladoras Ludmila da Silva Catela y Elizabeth Jelin, Siglo XXI, 2002, pp. 15-84. https://doi.org/10.14409/es.v27i1.2538

Dávalos-Sotelo, Raymundo. "Una forma de evaluar el impacto de la investigación científica”. Madera y Bosques, vol. 21, no. especial, 2015, pp. 7-16. https://doi.org/10.21829/myb.2015.210422

Estévez, EduardoE. "Reformandola inteligencia policial en la provincia de Buenos Aires". URVIO: Revista Latinoamericana de Estudios de Seguridad, no. 15, 2014, pp. 71-84. https://doi.org/10.17141/urvio.15.2014.1589

Fabbri, Paolo. El giro semiótico. Gedisa, 2000.

---. Tácticas de los signos. Gedisa, 1995.

Fabri, Silvina M. "Lugares de memoria y marcación territorial: sobre la recuperación de los centros clandestinos de detención en Argentina y los lugares de memoria en España". Cuadernos de Geografía - Revista Colombiana de Geografía, vol. 22, no. 1, 2013, pp. 93-108. https://doi. org/10.15446/rcdg.v22n1.36307 
Ferrari, Laura Daniela. "Marcadores de modalidad epistémica y evidencial en el análisis de las conclusiones de artículos de investigación de disciplinas distintas". ALED, vol. 9, no. 2, 2009, pp. 5-23. https://doi.org/10.35956/

Filinich, María Isabel. Enunciación. Eudeba, 2015.

Flier, Patricia. "Historia Reciente y desafíos de las fuentes: el Archivo de la Dirección de Inteligencia de la Policía de la Provincia de Buenos Aires (DIPBA)". Travesía, vol. 17, no. 2, 2015, pp. 81-88. https://doi. org/10.14409/cya.v1i12.1644

Flier, Patricia, y Emmanuel Kahan. "Los estudios de memoria y de la historia reciente: construcción de un campo, consolidación de una agenda y nuevos desafíos". La historia reciente en Argentina, compiladoras Gabriela Águila, Laura Luciani, Luciana Seminara y Cristina Viano, Imago Mundi, 2018, pp. 151-174. https://doi.org/10.19053/20275137. n19.2019.9580

Franco, Marina. "La historiografía de la historia reciente del Cono Sur". La historia reciente en Argentina, compiladoras Gabriela Águila, Laura Luciani, Luciana Seminara y Cristina Viano, Imago Mundi, 2018, pp. 175-196. https://doi.org/10.19053/20275137.n19.2019.9580

Funes, Patricia. "Ingenieros del alma. Los informes sobre canción popular, ensayo y Ciencias Sociales de los Servicios de Inteligencia de la dictadura militar argentina sobre América Latina". Varia historia, vol. 23, no. 38, 2007, pp. 418-437. https://doi.org/10.1590/s0104-87752007000200011

---. "Los libros y la noche. Censura, cultura y represión en la Argentina a través de los Servicios de Inteligencia del Estado". Dimensões, no. 19, 2007, pp. 133-155. https://doi.org/10.1590/s0104-87752007000200011

García Negroni, María Marta. "Subjetividad y discurso científico-académico. Acerca de algunas manifestaciones de la subjetividad en el artículo de investigación en español”. Signos, vol. 41, no. 66, 2008, pp. 5-31. https:// doi.org/10.1515/9783110929317-016

Gárgano, Cecilia. "Experimentación científica, genética aviar y dictadura militar en el Instituto Nacional de Tecnología Agropecuaria (1956-1976)". Mundo agrario, vol. 15, no. 28, 2014, pp. 1-31.

Genette, Gerard. Palimpsestos. La literatura en segundo grado. Taurus, 1989.

Ghigliani, Pablo. "Archivos policiales e historia social del trabajo (1957-1976)". Actas de las VII Jornadas de Sociología de la Universidad Nacional de La Plata "Argentina en el escenario latinoamericano actual: debates desde las ciencias sociales”, Universidad Nacional de La Plata, 2012. https://doi.org/10.35537/10915/70919 
González Quintana, Antonio. "Archivos y derechos humanos". Boletín de la ANABAD, vol. 49, no. 3, 1999, pp. 371-389.

---. Políticas archivísticas para la protección de los Derechos Humanos. Actualización y ampliación del informe elaborado para UNESCO y Consejo Internacional de Archivos (1995) sobre gestión de los archivos de los Servicios de Seguridad del Estado de los desaparecidos regímenes represivos. Consejo Internacional de Archivos, 2008. https://doi. org/10.7476/9789587385854.0012

Guglielmucci, Ana. La consagración de la memoria. Una etnografía acerca de la institucionalización del recuerdo sobre los crímenes del terrorismo de Estado en la Argentina. Antropofagia, 2013. https://doi.org/10.7440/ antipoda20.2014.08

Jaschek, Ingrid. "Informe de avance. mesa Doctrina". Mimeo. Comisión Provincial por la Memoria, 2003.

Jelin, Elizabeth. "Introducción. Gestión política, gestión administrativa y gestión histórica: ocultamientos y descubrimientos de los archivos de la represión". Los archivos de la represión: documentos, memoria y verdad, compiladoras Ludmila da Silva Catela y Elizabeth Jelin, Siglo XXI, 2002, pp. 1-13. https://doi.org/10.14409/es.v27i1.2538

---. La lucha por el pasado. Cómo construimos la memoria social. Siglo XXI, 2017. https://doi.org/10.4000/corpusarchivos.2039

Jimerson, Randall. "Embracing the power of archives". The American Archivist, vol. 69, no. 1, 2006, pp. 19-32.

Kahan, Emmanuel Nicolás. “¿Qué represión, qué memoria? El 'archivo de la represión' de la DIPBA: problemas y perspectivas”. Question, vol. 1, no. 16, 2007, pp. 1-10.

---. "Los judíos en los informes de la Dirección de Inteligencia de la Policía de la Provincia de Buenos Aires (DIPBA)". Estudios interdisciplinarios de América Latina y el Caribe, vol. 21, no. 2, 2010, pp. 33-60. https://doi. org/10.35537/10915/75497

Karababikián, Graciela. "Archivos y Derechos Humanos en Argentina”. Boletín del Archivo General de la Nación, vol. 32, no. 119, 2004, pp. 619-643.

Keck, Margaret E., y Kathryn Sikkink. "Transnational advocacy networks in international and regional politics". International Social Science Journal, vol.51, no. 159, 1999, pp. 89-101.https://doi.org/10.1111/1468-2451.00179

Kerbrat-Orecchioni, Catherine. La enunciación. De la subjetividad en el lenguaje. Edicial, 1993.

Lanteri, Magdalena, y Mariana Nazar. "Presentación de los instrumentos de descripción del fondo documental de la ex DIPPBA". Aletheia, vol. 5, no. 9, 2014, pp. 1-10. 
Lorenz, Federico Guillermo. “Archivos de la represión y memoria en la República Argentina”. Historizar el pasado vivo en América Latina, directora Anne Pérotin-Dumon, 2007, pp. 3-11. http://www.historizarelpasadovivo.cl/ index.html.

Luciani, Laura. "Catorce años de las Jornadas de Trabajo sobre Historia Reciente. Una mirada desde el presente". La historia reciente en Argentina, compiladoras Gabriela Águila, Laura Luciani, Luciana Seminara y Cristina Viano, Imago Mundi, 2018, pp. 197-214. https://doi. org/10.19053/20275137.n19.2019.9580

Maingueneau, Dominique. Introducción a los métodos de análisis del discurso. Hachette, 1980.

Marengo, María Eugenia. Lo aparente como real. Un análisis del sujeto "comunista" en la creación y consolidación del servicio de inteligencia de la policía de la Provincia de Buenos Aires. Tesis Magíster, Universidad Nacional de La Plata, 2012. https://doi.org/10.35537/10915/31868

---. "Los mecanismos del control social: el caso de la ex DIPBA". Derecho y Ciencias Sociales, no. 4, 2011, pp. 147-162.

Marengo, María Eugenia, y Sabrina Castronuovo. "El archivo policial como espacio de memoria: un sondeo por el ex archivo de la DIPPBA". Revista Electrónica de Fuentes y Archivos, vol. 6, no. 6, 2015, pp. 106-125. https://doi.org/10.24215/24691879e011

Martínez, Josebe. Exiliadas: escritoras, Guerra Civil y memoria. Montesinos, 2007.

Messina, Luciana. 'El ex centro clandestino de detención 'Olimpo' como dispositivo de memoria: reflexiones sobre las marcas territoriales y sus usos". Aletheia, vol. 2, no. 3, 2011, pp. 1-25.

Mitchell, Timothy. "Sociedad, economía y el efecto del Estado". Antropología del estado, Philip Abrams, Akhil Gupta y Timothy Mitchell, Fondo de Cultura Económica, 2015, pp. 145-187. https://doi.org/10.24201/ es.2016v34n102.1463

Nazar, Mariana. "Archivos, memoria y derechos: reflexiones en torno al caso argentino". Comma, no. 2, 2010, pp. 145-158. https://doi.org/10.3828/ comma.2010.2.12

Nora, Pierre. "Entre historia y memoria. La problemática de los lugares". Pierre Nora en Les lieux de mémoire. Trilce, 2009, pp. 19-39. https://doi. org/10.14361/9783839413272-050

Pacheco, Julieta. "La izquierda peronista y su inserción en el movimiento obrero". Revista Latino-americana de Estudos do Trabalho, vol. 19, no. 32, 2014, pp. 157-184. 
Pacheco, Julieta, y Guido Lissandrello. "Montoneros y el PRT-ERP: una propuesta comparativa a partir del análisis de sus posiciones frente al movimiento obrero (1973-1976)". Amérique Latine Histoire et Mémoire. Les Cahiers ALHIM, no. 26, 2013.

Pomian, Krzysztof. "Les archives. Du Trésor des chartes au Caran”. Les Lieux de Mémoire, III. director Pierre Nora, Gallimard, 1997, pp. 3999-4067.

Prieto Acosta, Diana Elena. "La inscripción explícita del autor en el discurso científico: análisis diacrónico y perspectivas". Universidad de La Habana, no. 279, 2015, pp. 6-21.

Rabotnikof, Nora. "Memoria y política a treinta años del golpe". Argentina, 1976. Estudios en torno al golpe de Estado, compiladores Clara Eugenia Lida, Horacio Gutiérrez Crespo y Pablo Yankelevich, Centro de Estudios Históricos del Colegio de México, 2007, pp. 259-284. https://doi. org/10.5354/0719-3734.2014.30899

Raina, Andrea. "Memorias e historiografía en torno al debate por la "violencia política' en la Argentina, 2003-2013". Revista de Sociología y Antropología: VIRAJES, vol. 18, no. 1, 2016, pp. 109-129.

Regueiro Rodríguez, María Luisa, y Sáez Rivera, Daniel M. El español académico. Guía práctica para la elaboración de textos académicos. Arco Libros, 2013. https://doi.org/10.14198/elua2014.28.17

Salas Valdebenito, Millaray. "Una propuesta de taxonomía de marcadores metadiscursivos para el discurso académico-científico escrito en español". Signos, vol. 48, no. 87, 2015, pp. 95-120. https://doi.org/10.4067/s071809342015000100005

Sánchez-Upegui, Alexánder Arbey. "Consideraciones sobre el artículo científico (AC): una aproximación desde el análisis de género y el posicionamiento". Lingüística y Literatura, vol.73,2018,pp. 17-36. https://doi.org/10.17533/ udea.lyl.n73a01

Scocco, Marianela. "Las fuerzas represivas y las divisiones de inteligencia. El Ejército y las policías en Rosario (1966-1979)". Revista de Estudios sobre Genocidio, vol. 14, 2019, pp. 11-28. https://doi.org/10.17141/ urvio.12.2012.1172

Slatman, Melisa. "Archivos de la represión y ciclos de producción de conocimiento social sobre las coordinaciones represivas en el Cono Sur". Taller (Segunda Época). Revista de Sociedad, Cultura y Política en América Latina, vol. 1, no. 1, 2012, pp. 47-66. https://doi.org/10.2307/j. ctvn96g1f.20

Tello, Andrés Maximiliano. Anarchivismo. Tecnologías políticas del archivo. La Cebra, 2018. https://doi.org/10.4000/corpusarchivos.3083 
Vaccari, Andrés. "El artefacto, ¿estructura intencional o sistema autónomo? La ontología de la función artefactual a la luz del intecionalismo, el dualismo y la filosofía de Gilbert Simondon". Revista Iberoamericana de Ciencia, Tecnología y Sociedad - CTS, vol. 7, no. 19, 2011, pp. 1-10. https://doi. org/10.1787/9789264200364-4-es

Verón, Eliseo. Fragmentos de un tejido. Gedisa, 2004.

Vezzetti, Hugo Mario. "Historia y memoria". Ciencia e Investigación, vol. 65, no. 4, 2015, pp. 23-27.

Villalta Luna, Alfonso Manuel. "The archives of terror and mourning in contemporary Spain". Culture \& History Digital Journal, vol. 3, no. 2, 2014, pp. 1-15. https://doi.org/10.3989/chdj.2014.021

Vitale, María Alejandra. "Vigiladores y espías. Imagen de sí, memoria y experticia en el Archivo de la DIPBA". Vigilar la sociedad. Estudios discursivos sobre inteligencia policial bonaerense, editora María Alejandra Vitale, Biblos, 2016, pp. 17-42. https://doi.org/10.22456/2594-8962.79468

Vitale, María Alejandra, y Adriana Minardi. "Memoria histórica, lugar de memoria y comunidad discursiva: materiales para el abordaje de un caso de archivo". Diálogos Latinoamericanos, vol. 20, 2013, pp. 72-96.

Vitale, María Alejandra, y María Elsa Bettendorff. "Memoria discursiva de "la subversión' según la DIPBA”. Estudios del Discurso, vol. 2, no. 1, 2016, pp. 1-21.

Zapata, Ana Belén. "Violencia parapolicial en Bahía Blanca, 1974-1976. Delgados límites entre lo institucional y lo ilegal en la lucha contra la "subversión apátrida"'. Anos 90, vol. 19, no. 35, 2012, pp. 111-140. https://doi.org/10.22456/1983-201x.29141 